\title{
SÍNDROME DE BARTTER. REPORTE DE UN CASO Y REVISIÓN DE LA LITERATURA
}

\author{
Juan José López Pérez, M.D. ${ }^{1}$, Luisa Fernanda Jaimes Martínez, M.D. ${ }^{2}$, \\ EDGar Fernando Galvis AlVARADo, M.D. ${ }^{3}$ \\ ${ }^{1}$ Pediatra Universidad Nacional de Colombia. Departamento de Pediatría, Hospital el Tunal, Bogotá, Colombia. \\ ${ }^{2}$ Médico y Cirujano Universidad Nacional de Colombia, Bogotá, Colombia. \\ ${ }^{3}$ Médico y Cirujano Universidad Militar Nueva Granada, Bogotá, Colombia.
}

\section{Resumen}

\begin{abstract}
Antecedentes. El síndrome de Bartter (SB) comprende un grupo detubulopatías caracterizadas principalmente por hipocalemia, alcalosis metabólica, hiperreninemia e hiperaldosteronismo, con presión arterial normal.Compromete principalmente la reabsorción de cloruro de sodio en la rama ascendente del asa de Henle, aunque en otras variantes, puede verse afectado el túbulo contorneado distal. Desde su primera descripción con el transcurrir de los años ya se han descrito seis variedades, lo que determina su heterogeneidad genética y expresividadvariable. Es una enfermedad rara con una prevalencia calculada en 1 por millón de habitantes. Esta enfermedad puede sospecharse y diagnosticarse antes del nacimiento, aunque en algunos casos, dependiendo de su presentación y de la acuciosidad del médico, su diagnóstico puede verse retrasado. Tanto el correcto y oportuno diagnóstico, como el adecuado manejo, pueden evitar muchas de sus complicaciones, las cuales pueden llevar incluso a la muerte.

Caso. Se presenta el caso de un lactante masculino de 14 meses de edad que consulta por vómito, astenia, adinamia y palidez generalizada. Ingresa con un peso de $5.4 \mathrm{~kg}$ y una talla de $69 \mathrm{~cm}$, marcada disminución del panículo adiposo y de la masa muscular, sin edemas. Los análisis reportaron potasio sérico 2,02 mEq/L, cloro $89,4 \mathrm{mEq} / \mathrm{L}$, sodio $134,5 \mathrm{mEq} / \mathrm{L}$, magnesio $2,39 \mathrm{mg} / \mathrm{dl}$, albumina 4,52 $\mathrm{gr} / \mathrm{dl}$, creatinina sérica $0,17 \mathrm{mg} / \mathrm{dl}$, uroanálisis con proteinuria $75 \mathrm{mg} / \mathrm{dl}$ y ecografía renal normal. Se sospecha síndrome de Bartter, por lo que se solicitan gases venosos que muestran $\mathrm{pH} 7,519, \mathrm{pO} 2$ $60 \mathrm{mmHg}$, pCO2 32,5 mmHg, HCO3 25,8 mmol/1, BE 3,3 mmol/L, relación calcio/creatinina en orina: 0,056 , aldosterona $11,9 \mathrm{ngr} / \mathrm{dl}$ y renina total $459 \mathrm{pg} / \mathrm{ml}$. Con estos resultados se hace el diagnóstico de SB, siendo compatible con el tipo III. Se iniciaron suplementos de potasio y diuréticos ahorradores de potasio sin lograr un adecuado aumento del potasio sérico y solo hasta iniciar indometacina este se logra corregir,al igual que la adecuada ganancia pondoestatural.A continuación se hace una revisión de la literatura sobre el síndrome de Bartter.

Conclusiones. El SB es una entidad poco frecuente, pero debe sospecharse cuando se presenta polihidramnios materno sincausa clara, crecimiento inadecuado sin evidencia dedesnutrición primaria u otros desórdenes gastrointestinales o endocrinológicos.
\end{abstract}

Palabras claves. Bartter, tubulopatía, hipocalemia.

* Correspondência: juanj.lopezp26@yahoo.es. Endereço: Hospital el Tunal, Carrera 20 No. 47B - 35 Sur. Bogotá - Colômbia, Telefone 7428585 Ramal 105.

Recibido: octubre 21 de 2011 Aceptado: noviembre 28 de 2011 


\title{
BARTTER SYNDROME - A CASE REPORT AND LITERATURE REVIEW
}

\section{Summary}

Background. The Bartter Syndrome (BS) includes a group of tubulopathies characterized mainly by hypokalemia, metabolic alkalosis, hyperreninemia and hyperaldosteronism, with normal blood pressure. It involves primarily the sodium chloride resorption in the ascending limb of the loop of Henle, although in other variants, the distal convoluted tubule can be affected. Since its first description, six varieties have been described over time, which determines its genetic heterogeneity and variable expression. It is a rare disease with an estimated prevalence of 1 per million people. This disease can be suspected and diagnosed before birth, though in some cases, depending on its presentation and the physician's thoroughness, the diagnosis can be delayed. Both the proper and timely diagnosis and the appropriate management can avoid many of its complications which can lead even to death. Case presentation. A case of 14-month male infant presenting with vomit, asthenia, adynamia, and generalized paleness is presented. At admission, his weight is $5.4 \mathrm{~kg}$ and height $69 \mathrm{~cm}$, with marked reduction of his adipose pannus and muscular mass, with no edema. The tests reported serum potassium $2.02 \mathrm{mEq} / \mathrm{L}$, chlorine $89.4 \mathrm{mEq} / \mathrm{L}$, sodium $134.5 \mathrm{mEq} / \mathrm{L}$, magnesium $2.39 \mathrm{mg} /$ $\mathrm{dl}$, albumin $4.52 \mathrm{gr} / \mathrm{dl}$, serum creatinine $0.17 \mathrm{mg} / \mathrm{dl}$, urinalysis with proteinuria $75 \mathrm{mg} / \mathrm{dl}$, and a normal renal echography. Bartter syndrome was suspected reason why venous gases were ordered which showed pH 7.519, pO2 $60 \mathrm{mmHg}$, pCO2 32,5 mmHg, HCO3 $25.8 \mathrm{mmol} / \mathrm{l}$, BE $3.3 \mathrm{mmol} / \mathrm{L}$, urine calcium/creatinine ratio 0.056 , aldosterone $11.9 \mathrm{ngr} / \mathrm{dl}$ and total renin $459 \mathrm{pg} / \mathrm{ml}$. With these results, the patient was diagnosed with BS, being compatible with type III. Potassium supplements and potassium sparing diuretics were started without achieving a proper serum potassium increase and only after starting indomethacine it could be corrected as well as the appropriate pondostatural increase. Below, there is a literature review about the Bartter syndrome.

Conclusions. The BS is a rare entity but it should be suspected when there is maternal polyhydramnios with no clear cause, inappropriate growth with no evidence of primary malnutrition or other gastrointestinal or endocrinological disorders.

Key words: Bartter, tubulopathy, hypokalemia.

\section{SÍNDROME DE BARTTER. RELATÓRIO DE UM CASO E REVISÃO DA LITERATURA}

\section{Resumo}

\begin{abstract}
Antecedentes. A síndrome de Bartter (SB) compreende um grupo de tubulopatias caracterizadas principalmente pela hipocalemia, alcalose metabólica, hiperreninemia e hiperaldosteronismo, com pressão arterial normal. Compromete principalmente a reabsorção de cloreto de sódio no segmento ascendente da alça de Henle, ainda que em outras variantes, pode ser afetado o túbulo contorcido distal. Desde sua primeira descrição com o transcorrer dos anos já foram descritas seis variedade, o que determina que sua heterogeneidade genética e expressividade variável. É uma doenças rara com uma prevalência calculada em 1 por milhão de habitantes. Esta doença pode suspeitar-se e diagnosticar-se antes do nascimento, ainda que em alguns casos, dependendo de sua apresentação $e$ do zelo do médico, seu diagnóstico pode ser atrasado. Tanto o correto e oportuno diagnóstico, como o adequado tratamento, podem evitar muitas de suas complicações, que podem levar inclusive à morte. Caso. Apresenta-se o caso de um lactante masculino de 14 meses de idade que consulta por vômito, astenia, adinamia e palidez generalizada. Dá entrada com um peso de $5.4 \mathrm{~kg}$ e uma estatura de $69 \mathrm{~cm}$, marcada diminuição do panículo adiposo e da massa muscular, sem edemas. Os exames mostraram potássio sérico 2,02 mEq/L, cloro $89,4 \mathrm{mEq} / \mathrm{L}$, sódio $134,5 \mathrm{mEq} / \mathrm{L}$, magnésio $2,39 \mathrm{mg} / \mathrm{dl}$, albu-
\end{abstract}


mina $4,52 \mathrm{gr} / \mathrm{dl}$, creatina sérica $0,17 \mathrm{mg} / \mathrm{dl}$, uroanálise com proteinúria $75 \mathrm{mg} / \mathrm{dl}$ e ecografia renal normal. Suspeita-se de síndrome de Bartter, por isso são solicitados gases venosos que mostram $\mathrm{pH}$ 7,519, pO2 60 mmHg, pCO2 32,5 mmHg, HCO3 25,8 mmol/l, BE 3,3 mmol/L, relação cálcio/ creatina na urina: 0,056 , aldosterona $11,9 \mathrm{ngr} / \mathrm{dl}$ e renina total $459 \mathrm{pg} / \mathrm{ml}$. Com estes resultados é feito o diagnóstico de SB, sendo compatível com o tipo III. Iniciaram-se suplementos de potássio e diuréticos economizadores de potássio sem obter-se um aumento adequado do potássio sérico, somente ao iniciar indometacina o mesmo é corrigido, da mesma forma que o adequado desenvolvimento pondoestatural. A seguir é feita uma revisão da literatura sobre a síndrome de Bartter.

Conclusões. A SB é uma entidade pouco frequente, mas deve-se suspeitar quando se apresentam polihidrâmnios materno sem causa clara, crescimento inadequado sem evidência de desnutrição primária ou outras desordens gastrointestinais ou endocrinológicas.

Palavras chave. Bartter, tubulopatia, hipocalemia.

\section{Caso clínico}

Paciente de 14 meses de edad, masculino, ingresa al servicio de urgencias pediátricas por fiebre no cuantificada de un día de evolución,vómito, astenia, decaimiento y palidez generalizada. El niño es fruto de la cuarta gestación, sin consanguinidad entre los padres, madre de 23 años, G4A2P2V2, quien presentó amenaza de aborto en el primer trimestre por infección de vías urinarias. Nació a las 38 semanas de gestación por vía vaginal, con peso al nacer de 3.100 g y talla de $52 \mathrm{~cm}$. Al mes de vida se hospitalizó por vómito, diagnosticándose reflujo gastroesofágico. Recibió lactancia materna exclusiva hasta los 6 meses, cuando el control mostró peso y talla para la edad en percentiles 3 y 25 respectivamente. A los 6 meses se inició dieta complementaria. A los 9 meses se observó un peso para la edad por debajo de percentil 3 y talla en el percentil 25, con neurodesarrollo normal.

Al examen físico de ingreso se observó marcada disminución de la masa muscular y del panículo adiposo, palidez cutánea, piel seca y descamativa, peso 5.400 $\mathrm{g}$, talla $69 \mathrm{~cm}$, sin edemas. Los laboratorios iniciales mostraron un potasio sérico de $2,02 \mathrm{mEq} / \mathrm{L}$, cloro $89,4 \mathrm{mEq} / \mathrm{L}$, sodio $134,5 \mathrm{mEq} / \mathrm{L}$, calcio iónico $1,151 \mathrm{mmol} / \mathrm{L}$, fosforo $5,0 \mathrm{mg} / \mathrm{dl}$, magnesio 2,39 $\mathrm{mg} / \mathrm{dl}$, albumina $4,52 \mathrm{~g} / \mathrm{dl}$, globulina $3,07 \mathrm{~g} / \mathrm{dl}$, nitrógeno ureico $9,5 \mathrm{mg} / \mathrm{dl}$, creatinina $0,17 \mathrm{mg} / \mathrm{dl}$, uroanálisis con proteinuria $75 \mathrm{mg} / \mathrm{dl}$, ecografía renal normal, sin nefrocalcinosis.

Teniendo en cuenta la hipocalemia asociada a su marcado retardo ponderal sin una causa clara, se sospecha síndrome de Bartter, se inicia suplencia de potasio, soporte nutricional y se amplían estudios. Se toma carotinemia: $105 \mu \mathrm{g} / \mathrm{dl}$ (normal 60-200 $\mu \mathrm{g} / \mathrm{dl}$ ), proteinuria de control $10,7 \mathrm{mg} / \mathrm{dl}$, potasio en orina $28,1 \mathrm{mEq} / \mathrm{L}$, fracción excretada de potasio de $45 \%$, cloro en orina de $89 \mathrm{mEq} / \mathrm{L}$, relación calcio urinario/ creatinuria en 0,056 , gases venosos con $\mathrm{pH} 7,519$, $\mathrm{pCO}_{2} 32,5 \mathrm{mmHg}$, HCO3 25,8 mmol/l, se toman muestras para aldosterona y renina acostado. Con suplencia de potasio de $6 \mathrm{mEq} / \mathrm{kg} /$ día, el potasio sérico de control permanece en $2,1 \mathrm{mEq} / \mathrm{L}$ por lo que se adiciona espironolactona a $1 \mathrm{mg} / \mathrm{kg} /$ día. A los 5 días de manejo el niño alcanza un peso de 5,700 g., pero el potasio sérico sólo aumento a $2,5 \mathrm{mEq} / \mathrm{L}$ a pesar de un aporte de potasio cercano a $6 \mathrm{mEq} / \mathrm{kg} /$ día y aumentar la espironolactona a $3 \mathrm{mg} / \mathrm{kg} /$ día. Al llegar el reporte de la aldosterona en $11,9 \mathrm{ng} / \mathrm{dl}$ (normal) y de renina total en $459 \mathrm{pg} / \mathrm{ml}$ (valor normal acostado 2,4-21,9 pg/ml), se diagnostica SB tipo III, por lo que se inicia indometacina a $2.2 \mathrm{mg} / \mathrm{kg} /$ día, logrando a los pocos días un potasio sérico de $3.4 \mathrm{mEq} / \mathrm{L}$. Se controla el paciente al mes de iniciada la indometacina observando un peso de $7.000 \mathrm{~g}$. (ganancia de 1.200 g. desde el egreso) y una talla de $73 \mathrm{~cm}$.

\section{Introducción}

Desde su primera descripción por Bartter y colaboradores, el conocimiento del SB ha aumentado gracias al desarrollo de la genética molecular. De una primera descripción, con el transcurrir de los años ya se han encontrado seis variantes, lo que determina su heterogeneidad genética. Igualmente, presenta heterogeneidad alélica y expresividad variable. Todas las alteraciones son ocasionadas por mutaciones en un solo gen (herencia monogénica), con patrón de 
herencia explicable según modelos mendelianos. Esta heterogeneidad clínica y genéticapuede requerir un análisis molecular para diferenciar sus diferentes variedades. Aunque aún faltan muchos procesos por entender, cada día crece el conocimiento sobre esta entidad, lo que permitirá en un futuro una aproximación diagnóstica más oportuna y un tratamiento óptimo.

\section{Consideraciones fisiológicas de importancia de la rama ascendente del asa de Henle y el túbulo contorneado distal para entender mejor el SB}

En riñones sanos se reabsorbe cerca del 99\% del sodio filtrado, ocurriendo el $60 \%$ en el túbulo proximal, el $30 \%$ en la porción gruesa de la rama ascendente del asa de Henle, el $5 \%$ en el túbulo contorneado distal y el resto en la nefrona distal sensible a la aldosterona (1). El 20\% del potasio filtrado se reabsorbe en la rama ascendente gruesa del asa de Henle (2).

La función principalde la rama ascendente gruesa del asa de Henle es la concentración de cloruro de sodio( $\mathrm{NaCl}$ en el intersticio medular, lo que contribuye a su hipertonicidad, requisito previo para el intercambio decontracorriente. Esto no solo genera retención de sodio, sino que también permite concentrar la orina (1)(3).Los defectos en este sitio originan una gran pérdida de sal y agua (3).

La absorción de sodio en la rama ascendente del asa de Henle se realiza principalmente por intermedio del cotransportador sodio-potasio-2cloro (NKCC2), que transporta aproximadamente el 50\%del sodio por vía transcelular, mientras que el otro 50\%tomaunaruta intercelularcatión selectiva (1). El cotransportador NKCC2 es electroneutro y transporta una molécula de sodio, una de potasio y dos de cloro, funcionando este transporte al interior de la célula solo cuando los cuatro lugares del transportador están ocupados (4). La absorción transepitelial de $\mathrm{NaCl}$ en ambos segmentos de la nefrona es impulsada por un gradiente electroquímico generada por procesos de transporte activo que dependen de una baja concentración de sodio intracelular que se mantiene gracias a la expulsión activa del sodio al espacio intravascular por la bomba de sodio-potasio ATPasa localizada en la membrana basolateral. La afinidad del transportador para el sodio y el potasio es muy alta, alcanzando casi la máxima actividad a concentraciones por debajo de 5 a 10
$\mathrm{mEq} / \mathrm{L}$, actuando el cloro como un factor limitante, ya que el transporte neto de $\mathrm{NaCl}$ aumenta al incrementar la concentración de cloro en el líquido tubular. Los diuréticos de asa como la furosemida, inhiben la reabsorción de $\mathrm{NaCl}$ al competir por el lugar donde el cloro se une al transportador (4). El potasio que entra por medio de este cotransportador se recicla de nuevo a la orina tubular de la medula renal a través del canal del potasio ROMK (1)(5), que es sensible al ATP y es electroneutro (6).La actividad de los canales de potasio son modulados por el ATP a través de la reabsorción de sodio, ya que cuanto más sodio entra a la célula, el transporte de este sodio fuera de la célula por la bomba sodio-potasio ATPasa ocasiona un aumento de consumo de ATP, lo que disminuye la relación ATP/ADP, liberando así la inhibición de los canales de potasio ROMK, permitiendo el retorno del potasio reabsorbido al espacio tubular (4)(5). El aumento del potasio a nivel tubular provee el potasio necesario para que el cotransportador NKCC2 realice la reabsorción de sodio y cloro (2). La acidificación citoplasmática inhibe también los canales ROMK. El aumento de los niveles de potasio séricos incrementa la densidad de los canales ROMK por intermedio de una kinasa inducida por la aldosterona (5). Así, la disponibilidad del potasio es otro paso limitante en la reabsorción del $\mathrm{NaCl}(7)$.

La secreción de potasio catión luminal junto con el cloro aniónico reabsorbido establece un gradiente positivo transepitelial(positivo a nivel tubular y negativo en la sangre) que facilita la reabsorción para celular de cationes como el sodio, calcio y magnesio (1)(4).Hay tres variantes del canal ROMK: ROMK1, ROMK 2 y ROMK3, con diferentes secuencias de aminoácidos terminales $\mathrm{NH}_{2}$. ROMK1, ROMK2, y ROMK3presentanidénticascaracterísticasbiofísicas y sus relevancias funcionales aún no han sido completamente aclaradas. Son expresados de manera diferente a lo largo de la nefrona para diferentes funciones fisiológicas. Los canalesROMK2, en la rama ascendente del asa de Henle,son los responsables del reciclaje del potasio través de la membrana apical, manteniendo la reabsorción de $\mathrm{NaCl}$ a travésdelcotransportadorNKCC2, importante para el mecanismo de concentración urinaria. Los canalesROMK1y el ROMK3,en la nefrona distal, constituyen un importante regulador de la secreción de potasio por elriñón, esenciales para el control de la excreción renal de este ion, logrando así mantener su equilibrio(5). Dos canales del cloro altamente homólogos, $\mathrm{ClC}-\mathrm{Ka}$ y $\mathrm{ClC}-\mathrm{Kb}$, expresados 
exclusivamente en el tejido renal humano pertenecientes a la familia de los canales del cloro voltaje dependientes CIC, están asociados con las subunidades beta barttina, necesarias para la adecuada inserción en la membrana plasmática del complejo que constituye el canal funcional(8),para así formar una conductancia basolateral del cloro, los cuales liberan la mayoría del cloro reabsorbido a la circulación sistémica (1). El $\mathrm{ClC}-\mathrm{Kb}$ es el que predomina (7), expresándose desde la rama gruesa ascendente hasta los túbulos colectores corticales (8) en las células intercaladas (9), pero principalmente en los segmentos más distales de la nefrona (7). El ClC-Ka, en cambio, predomina en la rama ascendente del asa de Henle, disminuyendo su expresión a lo largo de la nefrona distal adyacente (1).

En la región donde se unen la rama gruesa ascendente del asa de Henle y el tubo contorneado distal se encuentra la mácula densa. Las células de la mácula densa supervisan la concentración de $\mathrm{NaCl}$ en el líquido tubular y por medio de señalización paracrina con moléculas como la prostaglandina E2(PGE2), el ATP, la adenosina y el óxido nítrico,proporcionan un mecanismo de retroalimentación que se adapta ala filtración glomerular y ala reabsorción tubular (1).En caso de aumentar la concentración de $\mathrm{NaCl}$ enlamácula densa, se induce vasoconstricción de las arteriolas aferentes y se disminuye la liberación de renina, mientras que su disminución dilata las arteriolas aferentes y aumenta la liberación de renina. Para detectar la concentración de cloruro de sodio tubular, la mácula densa utiliza los mismos transportadores NKCC2, ROMK, CLC-K y barttina, que se traducen en alteraciones de la tensión transmembrana basolateral (1). El gradiente positivo transepitelial regula a su vez, entre otros procesos, la entrada del calcio sensible al voltaje, lo que desencadena una serie de eventos de señalización intracelular, finalmente resultando en la liberación de las citadas señales paracrinas (1). La hipocalemia estimula la producción de prostaglandinas, las cuales posteriormente activaran el eje renina, angiotensina II y aldosterona (10).En sentido contrario, la hipopotasemia inhibe la liberación de aldosterona (11).

El deterioro del transporte de sodio en cualquiera de estos segmentos de la nefrona causará una reducción permanente en el volumen extracelular, el cual a su vez generará la estimulación compensatoria de la secreción de renina $y$, por consiguiente, de angiotensina II y aldosterona, lo que ocasiona retención de sodio con aumento en la secreción de potasio e hidrogeniones. El cloro que acompaña al sodio no tiene un mecanismo compensador como el anterior, por lo que se pierde por la orina. En consecuencia, para mantener la electroneutralidad, el equilibrio lo dan otros cationes como el amonio y el potasio. La pérdida de amonio, el principal portador de protones en la orina, genera alcalosis metabólica y la pérdida de potasio agrava aún más la hipopotasemia causada por el hiperaldosteronismo secundario (1).

La alteración en la absorción del cloro en la rama ascendente del asa de Henle (la que es impermeable al agua) es esencial para generar la hipertonicidad del intersticio medular, para que en los conductos colectores, por intermedio de la vasopresina, se pueda reabsorber el agua, por lo que si no se reabsorbe el cloro habrá dificultad para concentrar la orina (12).

\section{Síndrome de Bartter}

Dos segmentosa lo largo de la porción distal de la nefrona están principalmente involucrados en la patogénesis del $\mathrm{SB}$ : la rama gruesa ascendente del asa de Henley el túbulo contorneado distal. Bartter y colaboradores describieron el síndrome en 1.962 . La basemolecular se empezó a revelar en1.995 y subsiguientemente sus diversas variedades, junto con las razones de su heterogeneidadf enotípica (7). Corresponde a una enfermedad hereditaria, autosómica recesiva para 5 de sus variantes y autosómica dominante para una de ellas, con 2 fenotipos y seis genotipos. La prevalencia estimada es de 1 por millón de habitantes(13), aunque en Costa Rica el Bartter neonatal se ha calculado en un caso por 100.000 nacimientos vivos al año. No tiene predilección por raza ni género (14).La presencia de polihidramnios sin una causa clara (diabetes gestacional o malformaciones fetales) debe hacer pensar en un SB (2)(12). Se debe preguntar sobre la consanguinidad de los padres.

Los rasgos fenotípicos representativos corresponden a individuos delgados, con músculos pequeños, cara triangular, frente prominente, ojos grandes y sobresalientes (9)(14), estrabismo (10), orejas puntiagudas, expresión en pucherocausada por la caída de los lados de la boca (14). El niño presentara decaimiento e hiporexia poco tiempo después del nacimiento (2). El aumento de las prostaglandinas puede generar fiebre de origen desconocido, vómito, diarrea, convulsiones $e$ infecciones recurrentes del tracto urinario (9). Todos los grupos tendrán retardo en el crecimiento. El 
retraso mental puede o no estar presente y generalmente es leve, aunque si el diagnóstico es temprano y el tratamiento oportuno el coeficiente intelectual puede ser normal (2). Los niños mayores pueden tener episodios recurrentes de deshidratación (10). En los múltiples casos descritos se ha visto que difirieren en la edad de inicio, la gravedad de los síntomas, el grado de retraso del crecimiento, la capacidad de concentración urinaria, la magnitud de la excreción urinaria de potasio y de prostaglandina, la presencia de la hipomagnesemia, la excreción de calcio en la orina (1) y el retraso mental (4).

El SB clásicamente se ha dividido en dos grandes grupos:

1. Bartter neonatal (también llamado síndrome de hiperprostaglandina E2),el cual es resultado de la alteración en la reabsorción de cloruro de sodio por un defecto en alguno de los canales NKCC2,ROMK, ClC-Kb (sólo o en conjunto con defectos en el canal $\mathrm{ClC}-\mathrm{Ka}$ ) ybarttina. En contraste con el canal $\mathrm{ClC}-\mathrm{Kb}$, no se han reportado defectos aislados en el canal $\mathrm{ClC}-\mathrm{Ka}$ en los seres humanos (8).

2. Bartterclásico, causado por la disfunción del canal CIC-Kb. Esta última alteración, como afecta al transporte de $\mathrm{NaCl}$ a lo largo de la rama gruesa ascendente del asa de Henle ya lo largo del túbulo contorneado distal, puede mimetizar el síndrome de Gitelman (SG) (1).

Algunos autores describen como Bartter tipo $\mathrm{V}$ la ganancia en la función del receptor sensor del calcio (CaSR) (7).

Recientementese ha propuesto una nueva clasificación de las tubulopatías hereditarias perdedoras de sal basada en su fármaco tipo, dividiéndolas en tres grupos (3)(15).

\section{Trastornos del asa:}

- Tipo L1, afecta el canal NKCC2 en la rama ascendente gruesa del asa de Henle, tipo furosemida.

- Tipo L2, afecta el canal ROMK en la rama ascendente gruesa del asa de Henle y el conducto colector cortical, tipo furosemida-amilorida.

\section{Trastornos del túbulo contorneado distal:}

- Tipo DC1, afecta el canal NCCT en el túbulo contorneado distal, tipo tiazida.

- Tipo DC2, afecta el canal ClC-Kb en el túbulo contorneado distal y en menor medida en la rama ascendente gruesa del asa de Henle, tipo tiazida-furosemida.

- Tipo DC3, afecta el canal Kir 4.1 en el túbulo contorneado distal, tipo tiazida.

\section{Trastornoscompuestos:}

- Tipo L-DC1, afecta los canales ClC-Ka yKb en la rama ascendente gruesa del asa de Henle y el túbulo contorneado distal, tipo furosemidatiazida.

- Tipo L-DC2, afecta la barttina en la rama ascendente gruesa del asa de Henle y el túbulo contorneado distal, tipo furosemida-tiazida.

El SB cursa principalmente con hipocalemia, aumento del potasio en orina, hipocloremia, aumento del cloro en orina ( $>40 \mathrm{mEq} / \mathrm{L}$ ), hipercalciuria con normocalcemia, aumento del sodio urinario con sodio sérico normal, alcalosis metabólica, hiperreninemia (10 a 20 veces los valores normales) con hipertrofia $e$ hiperplasia del aparato yuxtaglomerular, aumento en la producción de prostaglandinas vasodilatadoras como la $\mathrm{E}_{2}$ y la prostaciclina, hiperaldosteronemia, defecto en la capacidad de concentración renal y presión arterial normal (explicada en parte por el aumento de las prostaglandinas) (13).La reabsorción tubular distal del cloro es inferior al 60\% (normal mayor del 80\%) (16). El aumento de las prostaglandinas no es un hallazgo uniforme en el SB (14).La pérdida de volumen aumenta los niveles de renina y aldosterona (2). El aumento de la angiotensina II corresponde a un mecanismo compensatorio para mantener la presión arterial. Una infusión intravenosa rápida de solución salina puede revertir la insensibilidada la angiotensina y los niveles elevadosde renina volver a la normalidad, sugiriendo quela estimulación del sistema renina-angiotensina-aldosterona es secundaria a una depleción de volumen (17). La hipocalemia, la hipocloremia intracelular y la angiotensina estimulan la producción de prostaglandinas renales (9)(14). La inhibición del canalNKCC2enlamácula densa altera la concentración del cloro intracelular, lo que ocasiona una contracción de estas células, con la consiguiente activación de la ciclooxigenasa-2 (COX-2) y la 
prostaglandina $\mathrm{E}_{2}$-sintetasa. La sobreproducción de prostaglandina $\mathrm{E}_{2}$ interfiere con la retroalimentación tubulo glomerular, lo que ocasiona una desinhibición de la filtración glomerular, aumentando la tasa de filtración glomerular, ya que la mácula densa recibe una señal anormal de la aparente disminución del $\mathrm{NaCl}$ a nivel tubular. Igualmente, la prostaglandina $\mathrm{E}_{2}$ inhibe la acción de la hormona antidiurética a nivel del túbulo colector y activa el sistema reninaangiotensina-aldosterona, en un intento de aumentar la reabsorción de $\mathrm{NaCl}$, pero la $\mathrm{PGE}_{2}$ también inhibe la reabsorción de $\mathrm{NaCl}$ a nivel de la rama ascendente del asa de Henle por un mecanismo no aclarado (14), lo que agrava en últimas la pérdida de $\mathrm{NaCl}$ renal (3).

La hiperprostaglandinemia, además de estimular el sistema renina-angiotensina-aldosterona, estimula los sistemas adrenérgicos como mecanismos de control de la presión arterial (18). El aumento de laPGE ${ }_{2}$ renaltambiénpodría aumentar la liberación de cloro en la mácula densa. El aumento de las prostaglandinas estimula la producción del factor natriurético auricular (14) y de bradiquinina (19).La hiporeactividad vascular, a pesar del aumento en sangre de los niveles de renina, angiotensinalI, noradrenalina y de endotelina, probablemente se debe al aumento concomitante delas prostaglandinas, de la síntesis de óxidonítrico (7)(14), de la isoforma endotelial de óxido nítrico sintasa (18) y de bradiquinina (19). La hiporeactividad vascular mejora tras la corrección de la volemia y la administración de antiinflamatorios no esteroideos (AINES) (9).El aumento de la aldosterona no es la causa fundamental de la hipocalemia, ya que la adrenalectomía no la corrige, aunque si constituye un factor agravante (14)(17), ya que en el túbulo distal y en el conducto colector se reabsorbe sodio y elimina potasio.La hipercalciuria se explica por la alteración en la actividad delNKCC2, ya que el 25\%delcalciofiltradose reabsorbe en la rama ascendente del asa de Henle acoplada a la actividad del NKCC2. El deterioro en el transporte electrógeno del cloro alterará la reabsorción paracelular de calcio y magnesio, que se cree ocurre a través de una recientemente identificada proteína de unión renalllamadaparacelina- 1 . Como resultado de la pérdida de $\mathrm{NaCl}$, se produce un aumento compensatorio de la reabsorción de $\mathrm{NaCl}$ en el túbulo contorneado distal que inhibela reabsorción de calcio en este segmentoya grava aún más la pérdida de calcio en la orina. La hipercalciuria resultante conduce a hiperparatiroidismo secundario (14).La $1,25(\mathrm{OH})_{2} \mathrm{D}$ esta aumentada, pero las con- centraciones de 25-OHD, 24,25(OH) 2 , fósforo y paratohormona son normales, al parecer por un aumento en la hidroxilación de la 25(OH)D ocasionada por la estimulación de las prostaglandinas sobre la actividad de la 1alfa-hidroxilasa o por la pérdida renal de calcio que origina un incremento de los niveles de $1,25(\mathrm{OH})_{2} \mathrm{D}(20)$.

El aumento de la 1,25(OH) 2 Daumenta la absorción intestinal de calcio y la resorción ósea, acrecentando su eliminación urinaria (18)(21).Se ha sugerido que el proceso de reabsorción ósea y el aumento de la $\mathrm{PGE}_{2}$ mediada por el calcitriol, pueden contribuir a la hipercalciuria. Recientemente se ha sugerido que los niveles elevados de angiotensinall pueden estimularla síntesis del factor de crecimiento fibroblástico, con el consiguiente aumento de la resorción ósea a través de un mecanismo dependiente de las prostaglandinas (9). Esto genera una disminución de la masa ósea que está correlacionada con la intensidad de la hipercalciuria (21).La indometacina reduce los niveles de $1,25(\mathrm{OH})_{2} \mathrm{D}$ y la excreción urinaria de calcio (20). Se ha descrito hipofosfatemia por disminución de la reabsorción tubular de fosfato, posiblemente secundaria al daño tubular por la hipocalemia (9). La falta de hipermagnesuria es debida a un aumento compensatorio en la reabsorción de magnesio en el túbulo distal, el cual reabsorbe el 10\% del magnesio filtrado, que representa el 60 al 70\% del magnesio que llega a esa zona (1)(14), posiblemente favorecida por la mayor síntesis de prostaglandinas (9). Igualmente, en la rama ascendente del asa de Henle, esta adaptación puede implicar estructuras de unión apretadas como las claudinas 16 y 19 (9). La existencia de mutaciones con pérdida de función en la paracelina-1, que interviene en el transporte paracelular de cationes bivalentes a lo largo de la rama ascendente del asa de Henle, causará hipercalciuria e hipermagnesuria, dando lugar a hipomagnesemia y nefrocalcinosis. El defecto para concentrar y diluir la orina se debe a la hipocalemia y la alteración en la reabsorción de $\mathrm{NaCl}$ en la rama ascendente del asa de Henle, la cual es exacerbada por la sobreproducción de prostaglandinas (14). El aumento de la aldosterona estimula las células intercaladas del túbulo distal y conducto colector para el intercambio dehidrogeniones intracelulares por potasio intraluminal, aumentando la alcalosis metabólica debido a la pérdida de hidrogeniones (2).Probablemente, por la mayor producción de $\mathrm{PGE}_{2}$, la liberación de hormona antidiurética (ADH)disminuye, y esto, combinado con un aumento en la resistencia tubular a la 
acciónde la $\mathrm{ADH}$ por las lesiones tubulares causada por hipopotasemia (que son reversibles), conducen a una incapacidad para concentrar la orina, poliuria y polidipsia. La disminución del cloro sérico causa un aumento de la producción y reabsorción de bicarbonato buscando corregir el anión gap, lo que empeora la alcalosis metabólica (19). Existe una alteración en la agregación plaquetaria posiblemente por aumento de un metabolito de la prostaciclina, el 6 ceto $\mathrm{PGE}_{1}$.

Este defecto es aumentado durante la restricción de sodio y disminuido por la administración de los antiinflamatorios no esteroideos (AINES) (9). El aumento de la angiotensinall puede favorecer la fibrosis renal al aumentar la expresión del factor activador del plasminógeno-1 y como consecuencia, alterar la fibrinolísis vascular por estimulación de la TGF $_{1}$ y la producción de especies reactivas del oxígeno (22).

Este trastorno tiene características bioquímicas similares a las encontradas en pacientes tratados con diuréticos de asa, como la furosemida, la cual inhibe el cotransportador NKCC2 al unirse al sitio donde el cloro se une en dicho canal (4), en la porción de los dominios transmembrana 11 y 12 (9).

\section{Diagnóstico diferencial}

La excreción urinaria de cloro es esencial para poder diferenciar estas entidades (14). Con el uso crónico de diuréticos se presentará contracción de volumen, hipopotasemia,alcalosis hipoclorémica, hipertrofia del aparato yuxtaglomerular, niveles plasmáticos altos de prostaglandinas, renina y aldosterona,normotensión y aumento del cloro urinario, sin embargo, la reabsorción fraccional de cloro será normal, a diferencia de lo que sucede en el $\mathrm{SB}$, donde se encuentra disminuida (14). Un Bartter adquirido se puede presentar por uso de medicamentos como la gentamicina, anfotericina B, quimioterapia combinada y prostaglandinas en neonatos (manejo del ductus arterioso persistente). La presencia de vómitos cíclicos (bulimia, anorexia nerviosa, vómitos recurrentes), la administración de fórmulas bajas en cloro y el abuso de laxantes pueden simular un SB, generando hipomagnesemia, hipopotasemia, alcalosis metabólica, aumento de las prostaglandinas, hiperreninemia e hiperaldosteronismo (14), aunque aquí el cloro en orina estará disminuido (12). Igual sucede con la clorurorrea congénita, donde habrá hipocalemia y alcalosis metabólica, llegando al diagnóstico por las altas concentraciones de cloro en materia fecal (14). La fibrosis quística puede llevara alcalosis metabólica, deshidratación hipoclorémica, hiponatremia, hipopotasemiae hiperreninemia por la pérdida de cloro en sudor. El canal del cloro CFTR, que se encuentra mutado en la fibrosis quística, puede regular la función de ROMK en la rama ascendente del asa de Henle (9). Se diferencia del SB por la pérdida aumentada de cloro en sudor y la intensa reabsorción del mismo en los túbulos renales. La ausencia de hipertensión distingue el SB de otros trastornos renales y suprarrenales que se caracterizan por hipopotasemia, alcalosis y anormalidades en el sistema renina-aldosterona. La estenosis de la arteriarenal y los tumores secretores de renina se caracterizan por hiperreninemia e hiperaldosteronismo, generando hipertensión maligna. En los síndromes de Conn, hiperplasia suprarrenalnodular y aldosteronismo remediable con glucocorticoides presentan hiperaldosteronismo con supresión de la renina. La disfunción generalizada del túbulo proximal, como en el síndrome de Fanconirenal, secundario a una cistinosis o al síndrome de Kearns-Sayre, pueden tener características bioquímicas parecidas a un SB. Se ha reportado un caso de displasia renal familiar con alcalosishipopotasémica.

El síndromedeLiddle se caracteriza por alcalosis metabólica hipopotasémica con supresión de la aldosterona y la renina e hipertensión arterial. Los recién nacidos con la mutación ROMKsona menudo diagnosticados como pseudohipoaldosteronismotipo I.

Estos pacientes pueden tener inicialmente hiperpotasemia, acidosis metabólica y pérdida de $\mathrm{NaCl}$ grave. La hipopotasemia y la alcalosis metabólica típica de este síndrome pueden demorar en presentarse entre2semanasa20 meses, al parecer por un defecto en la secreción de potasio en el túbulo colector (14). Un defecto en la reabsorción de $\mathrm{NaCl}$ por disfunción del canal NCCT en el túbulo contorneado distal origina el síndrome de Gitelman (gen SLC12A3) (1), cuyo diagnóstico suele ser tardío ya que estos pacientes presentan síntomas y alteraciones metabólicas más leves, con hipopotasemia, alcalosis metabólica, hipomagnesemia, hipocalciuria( $<2 \mathrm{mg} / \mathrm{kg} / 24$ horas), capacidad de concentración urinaria y eliminación urinaria de prostaglandinas normales, aunque en ocasiones las manifestaciones pueden ser más graves y simular un SB (12). En algunos pacientes conSBel defecto de concentración urinaria es tan grave que 
puede conducir a hipernatremia, asemejándose a la diabetes insípida nefrogénica.

Otros pacientes con SB pueden no tener alcalosis metabólica durante el primer año de vida, o incluso presentar una acidosis metabólica transitoria con defecto en la acidificación urinaria, pudiendo parecer una acidosis tubular renal distal. El SB también se ha descrito en algunas enfermedades autoinmunes como en el síndrome de Sjögren. La asociación de $\mathrm{SB}$ con una silla turca parcialmente vacía detectada por resonancia magnética del cerebro ha sido reportada en adultos y niños (9). El síndrome EAST (epilepsia, ataxia, sordera neurosensorial y tubulopatía renal perdedora de sal) se debe a una alteración del gen KCNJ10 localizado en el locus del cromosoma 1q23.2(23).Este gen se expresa principalmente en el túbulo contorneado distal, en el túbulo conector y en el conducto colector cortical del riñón (3), aunque al parecer también en la rama gruesa ascendente. Su función es reciclar el potasio que entra a las células tubulares, lo cual es necesario para la adecuada función de la bomba $\mathrm{Na}+/ \mathrm{K}+\mathrm{ATPasa}$, lo que proporción aun mecanismo para regular indirectamente la reabsorción tubular renal de sodio, que modula la homeostasis del volumen y mantiene la presión arterial. El KCNJ10 también se expresa en las células gliales de la corteza cerebral, en la corteza cerebelosa y en los núcleos caudado y putamen. Se cree que sirve para establecer el potencial de reposo de las membranas de la red neuronal. Además, el KCNJ10 se expresa en células intermedias en la estría vascular y es necesario para la generación del potencial en dococlear, lo que sugiere que contribuye indirectamente con el enriquecimiento de potasio de la endolinfa. La enfermedad se inicia entre los 3 a 5 años. No ocasiona partos prematuros. Los pacientes afectados se presentan con crisis generalizadas tónico-clónicas en la infancia, retardo motor y del lenguaje, ataxia, temblor intencional y diadococinesia, resultados que son consistentes con disfunción cerebelosa y discapacidad auditiva.

El sistema renina-angiotensina-aldosterona se encuentra estimulado, con alcalosis metabólica hipopotasémica, hipomagnesemia e hipocalciuria, pero la capacidad de concentración urinaria no está muy alterada. No hay glucosuria ni proteinuria y la ecografía renal no evidencia nefrocalcinosis.La presión arterial se encontrará en los niveles inferiores de la normalidad para la edad y el sexo (23).

\section{Bartter neonatal o antenatal}

\section{Defectos en el canal NKCC2:}

También denominado Bartter tipo I, localizado en el gen SLC12A1 (OMIM 601678), cromosoma 15q15q21.1, proteína NKCC2 con pérdida de función (1), localizada en la rama ascendente del asa de Henle y en la mácula densa (9). El gen está formado por 26 exones (21), con 12 dominios transmembrana, de los cuales los dominios 2, 4 y 7 están relacionados con el transporte de iones (9). Cerca de 50 mutaciones se han descrito (24), principalmente por alteraciones en el marco de lectura sin sentido. Pueden ser heterocigotas compuestas u homocigotas. Es de destacar que el procesamiento alternativodelNKCC2por el pre-mRNA puede originar tresisoformasdeNKCC2, que difieren en sus características en el exón4, su localización a lo largo de la rama ascendente del asa de Henley en sutransporte.En consecuencia, se podría especular que las mutaciones que afectan a isoformas con baja-capacidad/alta-afinidad podría dar lugar a un fenotipo más leve (9). Estas mutaciones se manifiestan más como una disminución de la expresión de la proteína mutada que un defecto de inserción en la membrana tubular (21). Se calcula que una de cada 360 personas es portadora de un alelo mutante (16).Originalmente fue descrito como síndrome de hiperprostaglandina $\mathrm{E}_{2}(8)$.

Hacia el segundo trimestre de la gestación el feto presentará poliuria,lo que generará polihidramnios en la madre. Durante el embarazo, en el líquido amniótico las concentraciones de sodio, potasio, calcio y prostaglandina E son normales (2)(14), pero las concentraciones de cloro se pueden elevar hasta $118 \mathrm{mEq} / \mathrm{L}$., lo que, sin tratamiento, podrá conducir a un retardo en el crecimiento y parto prematuro hacia las 27 a 32semanas de gestación (1). También las concentraciones de aldosterona pueden estar altas en el líquido amniótico (9). La poliuria fetal puede llegar a ser mayor de $20 \mathrm{ml} / \mathrm{kg} / \mathrm{h}$. La hipercalciuria generará nefrocalcinosis, la cual puede ser detectada en el feto (14). Esta poliuria continúa después del parto y, por lo general, dura de 4 a 6 semanas, lo que puede generar rápidamente deshidratación, pérdida de $\mathrm{NaCl}$ y alcalosis metabólica,con la con secuente amenaza para la vida.

La pérdida de sodio puede durar varias semanas antes de que se convierta en pérdida renal de potasio, que 
puede explicarse por una maduración conjunta del túbulo proximal y distal, asociada a un marcado hiperaldosteronismo (14).Después de los primeros meses las perspectivas mejoran (14). La osmolaridad urinaria a penas se aproxima a la plasmática, lo que indica un grave defecto renal de concentración. Pero como la reabsorción de $\mathrm{NaCl}$ a lo largo de la rama ascendente del asa de Henle también es fundamental para la dilución de la orina, hace que la osmolaridad urinaria por lo general no caiga por debajo de $160 \mathrm{mosm} / \mathrm{kg}$.

Algunos conservan la capacidad para diluirla orina por un aumento de la función en la reabsorción de $\mathrm{NaCl}$ en el túbulo contorneado distal (1).En el primer mes de vida casi todos los pacientes desarrollan nefrocalcinosis medular con la presencia de una alta excreción urinaria de calcio. Generalmenteno se desarrollará hipomagnesemia.Puede llevar a la insuficiencia renal, desarrollando nefritis tubulo intersticial por la hipocalemia, la hipercalciuria, la nefrocalcinosis, la hiperreninemia, los episodios de deshidratación y el uso de los AINES, aunque en ocasiones puede ser reversible cuando sesuspenden estos últimos (9)(14). También se ha descrito glomerulonefritis proliferativa con fibrosis intersticial y glomeruloesclerosis segmentaria y focal cuando se ha desarrollado la insuficiencia renal crónica (14).

\section{Defectos en el canal ROMK:}

Corresponde al Bartter tipo II, gen KCNJ1 (OMIM 241200), cromosoma 11q24 (7), proteína ROMK(también conocida como Kir1.1) con pérdida de la función, localizada en la rama ascendente del asa de Henle y en el conducto colector cortical. Contiene 5 exones. Los canales ROMK son ensamblados a partir de cuatro subunidades, cada una con dosdominios transmembrana que flanquean un bucle que constituye un poro y filtro de selectividad, $y$ terminales citoplasmáticas $\mathrm{N}$ y $\mathrm{C}$ que contienen dominios reguladores (9).Pertenece a la familia de canales del potasio Kir, compuesto por siete subgrupos (25).Existen tres isoformas de la proteína ROMK que comparten un núcleo común de 372 aminoácidos codificados en el exón 5. La mayoría de la mutacionescausantes del SB neonatal están localizadas en el exón 5 (26).

Cerca de 50 mutaciones han sido identificadas (24), ocasionando pérdida de función, falta de apertura del canal o falta de expresión en la superficie celular (5). Estas mutaciones pueden generar interrupciónde la proteína previo al primer dominio transmembrana, alteración en el marco de lectura que resulta en una terminación prematura de la proteína, un cambio de sentido de la mutación que puede alterar la actividad óptima del canal o alteración en el marco de lectura generando una terminación prematura de la proteína (25). Las primeras mutaciones e informaron en el exón5, común a todas las isoformas ROMK, pero delecciones homocigotas en los exones1y2 también han sido descritas (9). Se calcula que una de cada 670 personas es portadora de un alelo mutante (16). Es un canal ATP sensible (27).Su disfunción no afecta las funciones de los canales NKCC2 y NCCT (20).

Generalmente habrá polihidramnios en la madre por la poliuria fetal, la prematuridad se presentará hacia las 33 semanas de gestación, insensibilidad a la vasopresina con poliuria, isostenuria e hipercalciuria con nefrocalcinosis secundaria (1), que en promedio se presenta a la edad de 2,5 meses (22).El eje renina, angiotensina y aldosterona estará activado. A pesar del hiperaldosteronismo, en los tres primeros días de vida se puede presentar hipercalemia asociada a hiponatremia (1)(12)en las dos terceras partes de los pacientes (22), al igual que acidosis metabólica (7), pudiendo confundirse con un hipoaldosteronismo o pseudohipoaldosteronismo tipo I. La hiperpotasemia inicial disminuye con la edad gestacional (1) y generalmente se normaliza en una (12) a varias semanas (7). La hiperpotasemia se puede a tribuir a un defecto en la secreción de potasio por la isoforma del canal ROMK que se expresa en el túbulo colector cortical (7), o a la falta de maduración al nacer de otros canales que secretan potasio independientes del ROMK, como el canal BK (canal maxiK) (5)(28). Aunque menos pronunciada en comparación con la deficiencia deNKCC2, la mayoría delos pacientes deficientes de ROMK desarrollan hipopotasemia en el curso de la enfermedad. La presencia dealcalosis distingue esta forma con el pseudohipoaldosteronismo, la insuficiencia suprarrenal o la hiperplasia suprarrenal congénita (29).

La hipercalciuria será marcada porque, en condiciones normales, la afluencia de cloro a través de NKCC2 y la salida de potasio a través de ROMK llevan a un exceso relativo de cargas positivas en la luz tubular lo que proporciona la fuerza motriz paracelular para la absorción de calcio y magnesio. Sin embargo, aunque la absorción de magnesio en la rama ascendente del asa de Henle también se reduce, la hipermagnesuria 
e hipomagnesemia son poco comunes debido a la estimulación compensatoria de la reabsorción de magnesio en el túbulo contorneado distal, probablemente inducida por las altas concentraciones de aldosterona. Esto también sucede en el Bartter tipo I (7). Estudios recientes indican que la hipopotasemia es menor que en aquellos con defectos en los canales NKCC2, ClC-Kb o NCCT y mejora con la edad (15).

\section{Defectos en la barttina:}

El Bartter tipo IV (denominado en OMIN 4A) es un defecto en el gen BSND (OMIM602522), cromosoma 1p31(7), proteína barttina con pérdida de función, localizada en la rama ascendente del asa de Henle y en el túbulo contorneado distal. Tiene 4 exones con dos dominios transmembrana (9)(17). La barttina es una subunidad critica que se encuentra en todos los canales $\mathrm{ClC}-\mathrm{K}$ expresados en las membranas basolaterales de los túbulos renales de las ramas ascendentes delgada y gruesa del asa de Henle, siendoesencia para la adecuada función del canalClC-Ka y $\mathrm{CIC}-\mathrm{Kb}$ ya que interviene en su estabilidad, facilita sutransporte e inserciónen la membrana plasmática y modula las propiedades biofísicas del canal ensamblado al complejo. Defectos en la barttina impiden así, indirectamente, la absorción y la salida de cloro de la célula a través de la membrana basolateral en la rama ascendente del asa de Henle y en túbulo contorneado distal, presentando elmás severo trastorno de pérdida renal de $\mathrm{NaCl}$ descrito hasta ahora (1)(30).Distintas mutaciones causan fenotipos de diferente severidad (30).

Se pueden presentar mutaciones sin sentido ( $R 8 \mathrm{~L}$, R8W y G10S) que eliminan la función del canal CIC-K/barttina, pero no impiden su inserción en la superficie de la membrana, otras mutaciones (G47R) permiten el funcionamiento de la barttina en el canal pero con una menor eficacia ya que disminuyen su número, la mutación sin sentido (E88X) hace quela misma cantidad de barttina se inserten las membranas basolateral y apical, en contraste con la inserción preferencial a pical de la barttina normal, y la mutación sin sentidoQ32Xpermite su asociación con los canales $\mathrm{ClC}-\mathrm{K}$ pero impide su inserción a la superficie de la membrana y la activación del canal (30). Las mutaciones que conducen a una pérdida del codón de inicio parecen estar asociadas con un curso más severo y deterioro precoz de la función renal. Por el contrario, la función renal se mantiene en todos los pacientes portadores de mutaciones que no impiden la inserción de la barttina en la superficie de la membrana (los pacienteshomocigotosconR8L, G10S, 11G47RomutacionesE88X). Pueden presentarse mutaciones heterocigotas compuestas como la Q32X con el aleloG47R, donde, en comparación con lospacientesG47Rhomocigotos, la insuficiencia renal se presentará hacia los 15 años. Todavía no se conocela interacción de la barttina con otras proteínas de membrana potencialmente involucradas en la preservación de la función renal, ya que la inserción residual de barttina en la membrana plasmática, incluso con discapacidad grave de la función delClC-K, puede proteger de la insuficiencia renal, posiblemente por el efecto de proteínas aún desconocidas y con una función similar de andamiaje observada para los canalesClC-K (30).

Genéticamente los canales CIC-Kb y CIC-Ka son normales (8). Habrá polihidramnios que se inicia hacia las 25 semanas, prematuridad antes de las 32 semanas de gestación, episodios de deshidratación, hipotensión hipovolémica, shock, poliuria, hipostenuria $e$ isostenuria, altas concentraciones de prostaglandinas en la orina (3)(8), defectos en el crecimiento, retraso psicomotor y sordera. Los pacientes desarrollarán insuficiencia renal al parecer secundaria a los múltiples episodios de deshidratación, hipocalemia crónica, perdida de $\mathrm{NaCl}$, uso de altas dosis de indometacina y por la enfermedad en si (7), manifestando esclerosis glomerular y atrofia tubular (9). El defecto de la barttina, localizada también en los canales del cloro en el epitelio del oído interno, ocasiona sordera neurosensorial ya que las células de la "stria vascularis" y el órgano vestibular contribuyen a la formación de la endolinfa por secreción apical de potasio, cuyo transporte transcelular es mediado por el cotransportador tipo $1 \mathrm{NaK} 2 \mathrm{CC}$ (NKCC1), asegurando la entrada basolateral de potasio en las células marginales. Los canales de potasio dependientes de voltaje median la secreción apical de potasio en la endolinfa.

El correcto funcionamiento del canal $\mathrm{NKCC} 1$ requiere del adecuado reciclaje basolateral del cloro, el que se encuentra alterado en los complejos CIC-barttina, lo que explicaría la hipoacusia (1). La hipocloremia es marcada, similar al defecto en el canal CIC-Kb (3).La hipercalciuria generalmente es leve y transitoria y no se presenta nefrocalcinosis. Esto podría deberse a defectos del transporte de $\mathrm{NaCl}$ tanto en el asa de Henle como en el túbulo contorneado distal, con efectos divergentes sobre la excreción de calcio urinario, de 
alguna manera similar a una acción combinada deun diurético como una tiazida. En consecuencia, en la deficiencia de barttina, los pacientes pueden mostrar una severa perdida de magnesio causada por el defecto en la reabsorción de magnesio tanto paracelular como transcelular (9). El fenotipo puede variar desde unas formas leve y de presentación más tardía a otras más severas y tempranas. La histología renal es de características variables e incluyen la hiperplasia de la paratoyuxtaglomerular, hipercelularidad mesangia lleve, fibrosis túbulo-intersticialmoderada a grave, zonas de atrofia tubular y glomérulosesclerosados (9).

\section{Defecto conjunto de los canales CIC-Ka y CIC-Kb:}

También denominado Bartter tipo VI (denominado en OMIM 4B). El ClC-Ka (gen CLCNKA) y el ClC-Kb (gen CLCNKB) (OMIM613090), proteína ClC-Ka/ $\mathrm{ClC}-\mathrm{Kb}$ con pérdida de función, se codifican en el cromosoma 1p36 de manera casi secuencial, pero su disfunción no se debe al síndrome de genes contiguos sino a alteraciones genéticas individuales en cada uno de ellos(8). Se ha descrito en muy pocos individuos (7). Defectos en ambos canales CIC-Ka y CIC-Kb, sin alteración en la barttina, generan una enfermedad indistinguible de la deficiencia de barttina. La madre presentará polihidramniospor la poliuria del feto, que comienza desde las 22semanas degestación, lo que llevará a un parto prematuro. Después del nacimiento los niños tienen alto riesgo de depleción de volumen y los niveles plasmáticos de cloro pueden disminuir hasta los $80 \mathrm{mmol} / \mathrm{L}$. La poliuria es resistente a la vasopresina y las osmolalidades en orina oscilan entre$200 y 400 \mathrm{mosm} / \mathrm{kg}$ (1). Habrá altas concentraciones de prostaglandinas en la orina (8).La hipocalemia se presenta en los primeros días de vida (8). La hipercalciuria es transitoria y la nefrocalcinosis estará ausente, al parecer secundarios a una disfunción en la reabsorción del sodio en el canal NCCT del túbulo distal, causa del síndrome de Gitelman, que causa hipocalciuria, lo que compensaría la hipercalciuria de la disfunción de la rama ascendente del asa de Henle.

La hipomagnesemia es importante y se presenta por alteración en la reabsorción paracelular en la rama ascendente del asa de Henle y transcelular en el túbulo contorneado distal. La insuficiencia renal progresiva es frecuente, no siendo bien entendida. Se presenta esclerosis glomerular y atrofia tubular con infiltración de células mononucleares (1). Los individuos afectados presentarán hipoacusia (8).

\section{Bartter clásico}

\section{Defectos en el canal CIC-Kb:}

Denominado Bartter tipo III, gen CLCNKB (OMIM607364) en el cromosoma 1p36 (7),cuya proteína CIC-Kb contiene 19 exones (9), 687 aminoácidos y 12 dominios transmembrana (21), siendo descritos varios tipos de mutaciones como grandes y pequeñas delecciones, pequeñas inserciones $y$, especialmente, mutaciones sin sentido con pérdida de función (14)(24). Existe una alta tasa de delecciones que abarcan una parte o la totalidad del gen CLCNKB. La estrecha vecindad de los genes casi idénticos CLCN-KayCLCN-Kb, separados solo por $11 \mathrm{~kb}$, predispone a una alta tasade reordenamientos por un entrecruzamiento desigual. Este canal se localiza tanto en la rama ascendente del asa de Henle como en, principalmente, el túbulo contorneado distal (1). Requiere de la subunidad beta barttina para facilitar su inserción en la membrana plasmática y para generar las corrientes del cloro (7)(9).

Afecta principalmente y con mayor intensidad a los afroamericanos, pudiendo llevar, especialmente en este grupo étnico, a una insuficiencia renal crónica. El defecto aislado del gen $\mathrm{ClC}-\mathrm{Kb}$ puede generar fenotipos variables, no existiendo una correlación entre genotipo y fenotipo. Aún en la ausencia del genClC-Kb, que afecta a casi el $50 \%$ de los pacientes, la enfermedad puede cursar con diversos grados de gravedad. Las características de presentación son principalmente las relacionadas con el túbulo contorneado distal.Su disfunción altera las concentraciones del cloro intracelular causando disfunción secundaria de otros canales, principalmente el canal NCCT y, en menor medida, en el canal NKCC2 (15). Vías alternativas en el transporte de cloro-potasio, como la no alteración del canal ClC-Ka, permitirían una compensación parcial, siendo la enfermedad menos grave que la forma neonatal (1)(7)(18), aunque tales opciones de rescate no existen en el túbulo contorneado distal (3).

Clínicamente se puede comportar ya sea como un Bartter neonatal, un Bartter clásico o un síndrome de Gitelman con hipomagnesemia e hipocalciuria (9)(15) (24). Incluso, dos hermanos con la misma alteración genética pueden presentarse con diferente fenotipo, por ejemplo, uno como Bartter antenatal y el otro como Bartter clásico (22). La heterogeneidad feno- 
típica también podría deberse a variación individual en la distribución del canalClC-Kben la nefronadistal o a una potencial activación de vías alternativas para la secreción basolateral de cloro (3).No se presentará sordera porque lafunción de los canales $\mathrm{ClC}-\mathrm{Kb} /$ barttina en el oído interno puede ser reemplazada por los canalesClC-Ka/barttina (9).El polihidramnios materno se observa en cerca del 25\% de los casos y por lo general es leve, lo que hace que la duración del embarazo sea generalmente normal (38 semanas en promedio). Más de la mitad de los pacientes son diagnosticados en el primer año de vida.Los síntomas iniciales pueden ser muy variables e incluyen retraso en el crecimiento, retraso en el desarrollo intelectual, fácil deshidratación, poliuria (no siempre presente), polidipsia, enuresis, gusto por la sal, vómito, episodios de fiebre inexplicable,c constipación, debilidad muscular y letargia (9)(14)(21). Puede presentarse osteopenia con aumento de los marcadores de reabsorción ósea (9).

El laboratorio mostrará hipocloremia (hasta $60 \mathrm{mmol} / \mathrm{L}$ ), hiponatremia, hipocalemia y alcalosis metabólica. La pérdida lenta y progresiva de sal con ausencia de poliuria puede retrasar la consulta médica. La actividad de la renina plasmáticaesmuchomayor, mientras quela concentración plasmática de aldosterona sólo está ligeramente elevada, aunque puede ser normal o incluso baja. Esta discrepancia se atribuye al a retroalimentación negativa de la secreción de aldosterona por la marcada hipocalemia y la alcalosis metabólica. La isostenuria e hipostenuria se presenta en un tercio de los pacientes, existiendo cierta capacidad para concentrar la orina, pudiendo llegar a más de 700 mosm/L en horas de la mañana, lo que indica que la hipertonicidad a nivel del intersticio medular renal está conservada. La excreción urinaria de calcio generalmente es normal o,incluso, a veces baja, y si se presenta hipercalciuria (solo presente en cerca del $20 \%$ de los casos) generalmente es transitoria, por lo que la nefrocalcinosis no es común (1) (29), cuya explicación aún no está aclarada (14). Con respecto al Bartter tipo I, II y IV, estos pacientes son los que manifiestan una mayor hipocalemia, hipocloremia y más alta bicarbonatemia (22).

Puede haber una leve hipofosfatemia explicada por el daño tubular generado por la hipocalemia (9). La ecografía renal no mostrará nefrocalcinosis, pero pueden observarse pequeños quistes medulares se- cundarios a la hipocalemia crónica (21). En el 20\% de los casos la concentración plasmática de magnesio disminuye gradualmente con el tiempo, como se observa en las alteraciones del túbulo contorneado distal, asemejando el SG (1)(21). La hiperuricemia se presenta en el 50\% de los casos y se debe a la contracción del volumen extracelular (21). El péptido natriurético auricular esta aumentado, a pesar de la hipovolemia, por el hiperprostaglandismo (21). Otras alteraciones bioquímicas ocasionales son la policitemia y la hipercalcemia.

En la orina la excreción fraccional de cloro, sodio y potasio están aumentadas y una concentración de cloro en orina mayor de $10 \mathrm{mEq} / \mathrm{L}$ en un paciente con alcalosis hipocalémica facilita el diagnóstico diferencial con pérdidas de cloro extrarenales. La reabsorción tubular distal de cloro será menor del 60\%. La excreción urinaria de prostaglandina $\mathrm{E}_{2}$ y del metabolito principal de la prostaciclina 6-ceto-PGE-1alfa estará aumentada (21). La insuficiencia renal es rara (14).

Aunque las concentraciones extracelulares de potasio son bajas, los cambios electrocardiográficos no son prominentes y las arritmias son poco frecuentes (14), aunque si se presentan pueden ocasionar muerte súbita (21). El aumento de las prostaglandinas puede dar lugar a un trastorno en la agregabilidad plaquetaria, lo que debe tenerse en cuenta en caso de requerir biopsia renal (21).La recuperación del crecimiento y la estatura normal, la edad ósea y el desarrollo puberal se puede obtener con laterapia adecuada. Puede haber un compromiso importante en el desarrollo neurointelectual, aunque generalmente es leve y la mayoría de los pacientes pueden asistir a la escuela regular (14).

En algunos pacientes pueden tener déficit aislado de hormona del crecimiento (21).La proteinuria no es frecuente (9). En etapas tempranas la filtración glomerular será normal, pero en algunos casos se puede ir desarrollando insuficiencia renal crónica debido al efecto fibrinogénico de la angiotensina II (21). A nivel renal habrá hiperplasia del aparato yuxtaglomerular y en ocasiones hiperplasia de células intersticiales renomedulares. Con el tiempo se puede ir presentando cierto grado de nefropatía túbulo intersticial crónica con hialinosis glomerular, v acuolización apical de las células tubulares proximales, atrofia tubular y fibrosis intersticial (21). 


\section{Síndrome de Bartter asociado con hipocalcemia}

\section{Defectos en el receptor sensor del calcio CaSR:}

También denominado Bartter tipo $\mathrm{V}$, es un defecto en el gen CaSR (OMIM 146200), localizado en el cromosoma 3q13.3-q21, cuyo producto es la proteína CaSR. Consta de 6 exones con 1.078 aminoácidos y 7 dominios transmembrana. Se pueden presentar mutaciones puntuales, delecciones de algunos pares de bases o inserción de secuencias de aminoácidos (31).Es el único que tiene una herencia autosómica dominante y aumento de su función (7). Es un miembro de la familia de receptores acoplados a la proteína $G$ (32). La actividad del canal ROMK está regulada por el receptor sensible al calcio. Este receptor se expresa en la glándula paratiroidea que secreta la hormona paratiroidea, en las células $C$ del tiroides que secreta la calcitonina, en el intestino, en los huesos y a nivel renal especialmente en la membrana basolateral de las células tubulares de la rama gruesa ascendente cortical del asa de Henle y el túbulo contorneado distal (9)(33), pero también, en menor extensión (34), en la superficie luminal en el túbulo proximal y los conductos colectores (33).

Dentro de sus funciones a nivel renal están la homeostasis del calcio y el fósforo, transporte de cationes mono y bivalentes, acidificación urinaria, concentración de la orina y liberación de renina (33). Regula negativamente la reabsorción del sodio (5). Es activado por las altas concentraciones intersticiales de calcio y/o magnesio, lo que aumenta el calcio citosólico por liberación de sus depósitos intracelulares y la apertura de los canales del calcio, lo que disminuye el AMPc por inhibición de la adenilato ciclasa. La reducción de los niveles de AMPc inhiben los canales ROMK necesarios para el reciclaje del potasio, esencial para la adecuada función del cotransportador NKCC2, por lo que disminuye el transporte de $\mathrm{NaCl}$, alterando el voltaje transepitelial (positivo en el lumen y negativo en la sangre), llevando a una disminución de la reabsorción de calcio y magnesio.

Además, la activación del CaSR inducida por el calcio, conduce ala producción de ácido araquidónico y sus metabolitos, los que inhiben la actividad de los canales ROMK y NKCC2, reduciendo aún más el transporte de calcio y magnesio (9).A mayor hipercalcemia mayor inhibición de los canales ROMK. La alcalinización aumenta la afinidad del receptor CaSR por el calcio y el magnesio y la acidificación la disminuye (33). La activación del CaSR altera la translocación de la acuaporina2(disminuye la expresión de la proteínaAPQ2 por un mecanismo postranscripcional) en el conducto colector medular, produciendo un efecto diurético y disminuyendo la capacidad de concentración urinaria, produciendo un cuadro clínico similar a una diabetes insípida nefrogénica (33).Más de20mutacionesdiferentesdelgenCaSR han sido descritas, especialmente con pérdida de sentido. Alrededor de la mitad de estas mutaciones se encuentran en el dominio extracelular del CaSR. Mutaciones con ganancia de función del CaSR darán lugar a hipocalcemia con hipercalciuria y nefrocalcinosis por inhibición concomitante de la hormona paratiroidea y pérdida de sal a nivel renal, lo que ocasiona un síndrome similar al Bartter (7)(34).

Las mutaciones L125P, C131WyA843E generan una activación de los receptores más grave en comparación con otrasmutacionesdescritas. LamutaciónA843Ees la única mutación descrita en el CaSR que presenta una alta actividad basal en ausencia de calcio (34). Se asocia con hipoparatiroidismo debido a que el CaSR también se localiza en la glándula paratiroidea, disminuyendo la secreción de la paratohormona (35). Cursa con hipocalemia con pérdida renal de potasio, hiperaldosteronismo, hiperreninemia y nefrocalcinosis (31)(33) a pesar del aumento en la excreción urinaria de magnesio (9). Cerca del 50\% de los pacientes tienen hipomagnesemia y el fósforo sérico estará normal alto o alto (9). El receptor CaSR se expresa en las células del aparato yuxtaglomerular y su activación disminuye la secreción de renina por supresión de la actividad de la adenilato ciclasa V.

Otros factores,como un aumento distal de $\mathrm{NaCl}$ o la acidificación sostenida ,podrían afectarla producción de renina Esto coincide con el fenotipo de Bartter tipo $\mathrm{V}$, donde los niveles de renina y aldosterona están altos y la presión arterial es normal o baja (33). Esta forma se distingue del Bartter clásico por la presencia de hipocalcemia, hipercalciuria e hipomagnesemia. Igualmente, se distingue de otras variantes de hipoparatiroidismo por la presencia de hipercalciuria durante lahipocalcemia (12). Se pueden presentar espasmos carpopedales y convulsiones por la hipocalcemia (32), la cual generalmente es leve a moderada (9), al igual que poliuria (3). 


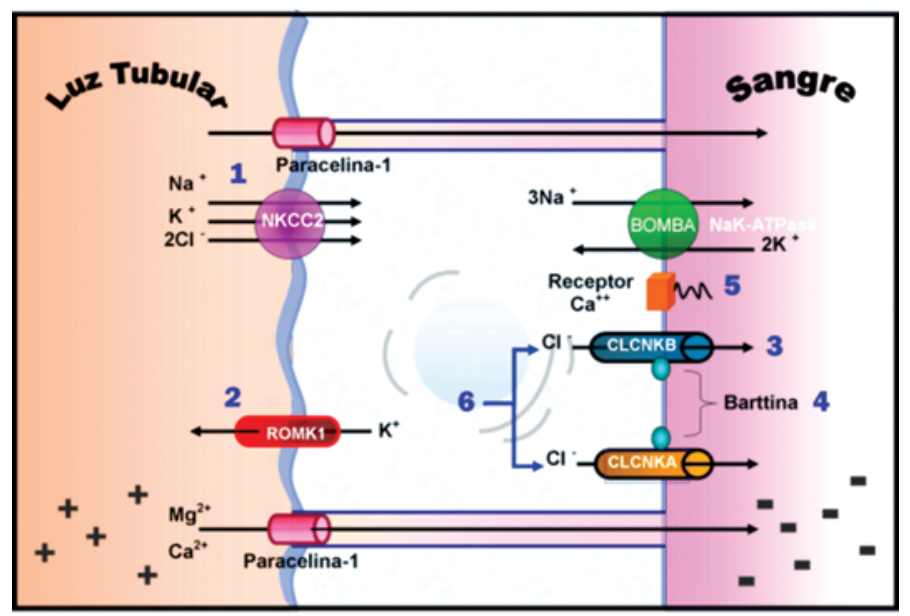

Resumen de los hallazgos clínicos y bioquímicos en el SB

\begin{tabular}{|c|c|c|c|c|c|c|}
\hline Características & Bartter I & Bartter II & Bartter III & Bartter IV & Bartter V & Bartter VI \\
\hline Edad de inicio & Antenatal & Antenatal & Variable & Antenatal & Variable & Antenatal \\
\hline Polihidramnios materno & Presente & Presente & Raro & Presente & & Presente \\
\hline Prematuridad & Presente & Presente & Rara & Presente & & Presente \\
\hline Falla para crecer & Presente & Presente & Común & Presente & & Presente \\
\hline Retardo del crecimiento & Presente & Presente & Común & Presente & & Presente \\
\hline Espasticidad, tetania, debilidad muscular & Ausente & Ausente & Ocasional & Ausente & Variable & Ausente \\
\hline Nefrocalcinosis & Presente & Presente & Rara & Ausente & & Ausente \\
\hline Hipoacusia neurosensorial & Ausente & Ausente & Ausente & Presente & Ausente & Presente \\
\hline Episodios de deshidratación & Severa & Severa & Severa & Severa & & Severa \\
\hline Alcalosis metabólica hipocalémica & Presente & $\begin{array}{l}\text { Presente (hiper- } \\
\text { calemia neonatal } \\
\text { transitoria) }\end{array}$ & Presente & Presente & Presente & Presente \\
\hline Magnesio plasmático & Normal & Normal & $\begin{array}{l}\text { Normal o } \\
\text { bajo }\end{array}$ & $\begin{array}{l}\text { Normal o } \\
\text { bajo }\end{array}$ & $\begin{array}{l}\text { Normal o } \\
\text { bajo }\end{array}$ & Normal o bajo \\
\hline Excreción urinaria de calcio & Alta & Alta & $\begin{array}{l}\text { Usualmen- } \\
\text { te normal }\end{array}$ & $\begin{array}{l}\text { Moderada } \\
\text { (transitoria } \\
\text { o normal) }\end{array}$ & Alta & $\begin{array}{l}\text { Moderada } \\
\text { (transitoria o } \\
\text { normal) }\end{array}$ \\
\hline Excreción urinaria de cloruro de sodio & Alta & Alta & Variable & Muy alta & Alta & Muy alta \\
\hline Máxima osmolalidad urinaria & Hipostenuria & Hipostenuria & $\begin{array}{l}\text { Usualmen- } \\
\text { te normal }\end{array}$ & $\begin{array}{l}\text { Iso/ hipos- } \\
\text { tenuria }\end{array}$ & & $\begin{array}{l}\text { Iso/hipostenu- } \\
\text { ria }\end{array}$ \\
\hline Alta renina/ aldosteronismo & Presente & Presente & Presente & Presente & Presente & Presente \\
\hline Excreción urinaria de prostaglandina E2 & Muy alta & Muy alta & $\begin{array}{l}\text { Ligeramen- } \\
\text { te elevada }\end{array}$ & Alta & Elevada & Alta \\
\hline Poliuria & Presente & Presente & Ocasional & Presente & Variable & Presente \\
\hline
\end{tabular}




\section{Diagnóstico}

La historia clínica constituye una parte fundamental del diagnóstico. Se debe interrogar la consanguinidad de los padres. Las manifestaciones prenatales más graves sugerirán un trastorno de asa. El polihidramnios materno excesivo (3 a 15 litros)y, a menudo, la necesidad de una amniocentesis, la poliuria masiva en la infancia temprana( $>15 \mathrm{ml} / \mathrm{kg} /$ día) con una osmolaridad urinaria $<300 \mathrm{mOsm} / \mathrm{kge}$ hipercalciuria persistente (>8 mg/kg/día)con nefrocalcinosis son indicativos de los desórdenes del asa de Henle. Por el contrario,hipocalciuria( $<2 \mathrm{mg} / \mathrm{kg} /$ día) con una osmolaridad urinaria $>400 \mathrm{mOsm} / \mathrm{kg}$, asociados a irritabilidad neuromuscular y tetania, en pacientes no muy jóvenes o en edad escolar,sugiere fuertemente un trastorno del túbulo contorneado distal (3).La hipercalemia transitoria sugerirá un Bartter tipo II, la hipocalcemia un Bartter tipo $\mathrm{V}$ y la presencia de hipoacusia un Bartter tipo IV o VI (3).

\section{Laboratorios de importancia en el SB:}

Los gases sanguíneos mostrarán una alcalosis metabólica. A pesar de esto, el pH urinario será menor de 6 a consecuencia de que la aldosterona reabsorbe sodio y elimina potasio o hidrogeniones (29).

La renina y la aldosterona estarán elevadas, secundarias a la contracción del volumen intravascular (29).En el Bartter tipo III la aldosterona puede estar normal debido al bloqueo que produce en su secreción la hipocalemia severa.

El potasio sérico estará disminuido, aunque en el Bartter tipo II podrá estar elevado en las primeras semanas de vida. El potasio en orina, en cambio, estará elevado. Para un individuo con función renal normal y una ingesta de potasio promedio, la fracción excretada de potasio (FEK) es aproximadamente del 10\% $(8,43$ $\pm 3,24)$. Cuando la hipocalemia es debida a causas extrarrenales, el riñón conserva potasio y la FEK es baja. Si no se dispone de una depuración de creatinina, en los pacientes hipocalémicos un potasio urinario mayor de $20 \mathrm{mEq} / \mathrm{L}$ sugiere una etiología renal.

\section{Fracción excretada de potasio:}

$$
\mathrm{FEK}=\frac{\mathrm{UK} \times \mathrm{PCr}}{\mathrm{UCr} \times \mathrm{PK}}
$$

FEK: Fracción excretada de potasio.

UK: Potasio urinario.

PK: Potasio plasmático.

PCr: Creatinina plasmática.

UCr: Creatinina urinaria.

El aumento de la secreción de potasio a nivel renal se puede demostrar por la medición del gradiente transtubular de potasio, el cual es una medida indirecta de la actividad de la aldosterona plasmática:

\section{Concentración transtubular de potasio:}

$$
\mathrm{CTK}=\frac{[\mathrm{K}] \mathrm{u} \times \mathrm{OsmP}}{[\mathrm{K}] \mathrm{s} \times \mathrm{OSM} \mathrm{U}}
$$

CTK: Concentración transtubular de potasio.

[K]u: Concentración de potasio en orina.

[K]p: Concentración de potasio en plasma.

Osm P: Osmolaridad plasmática.

Osm U: Osmolaridad urinaria.

Los valores normales van de 4 a 8 , pero en el SB, como en los estados de hiperaldosteronismo, están entre 10 a 13, indicando una pérdida de potasio por orina inapropiadamente alta (29).

Con respecto al calcio, en el Bartter tipo I, II y V habrá hipercalciuria, en el Bartter tipo III el calcio en orina generalmente será normal o bajo y en el Bartter tipo IV y VI la hipercalciuria podrá no estar presente y si lo está será moderada y generalmente transitoria. La hipercalciuria se identifica por la presencia de más $\mathrm{de} 4 \mathrm{mg} / \mathrm{kg}$ de calcio en orina de 24 horas o en una muestra aislada de orina una relación calcio en $\mathrm{mg} \%$ / creatinina en $\mathrm{mg} \%$ mayor a 0,8 en menores de 6 meses, a 0,6 en niños entre 7 y 12 meses, a 0,47 en menores de 2 años y a 0,21 en niños mayores de 2 años (36), pero se ha visto que estos resultados pueden estar influidos por la dieta, el origen étnico, la edad y la región, por lo que muestras aleatorias de orina no siempre se correlacionan con la recolección de orina de 24horas (37).

El cloro sérico estará disminuido con un cloro urinario aumentado. La reabsorción fraccional de cloro está alterada en el SB, estando en cerca del 60\%, cuando lo normal es que esté por encima de 80\% (14). 
A nivel urinario las prostaglandinas y la calicreina están aumentadas, aunque a nivel plasmático las concentraciones de prostaglandina E2 y la F2alfa son normales (14).

En el SB habrá osteopenia, elevación de la 1-25 dihidroxivitamina $\mathrm{D}$, pero la paratohormona tendrá niveles séricos normales (14).

La respuesta a los diuréticos para valorar la fracción excretada de cloro se ha utilizado para diferenciar los distintos tipos de Bartter y elSG. Así, los pacientes con defectos en el canal NKCC2no tendrán una respuesta a la furosemida, aquellos con un defecto en elNCCTno mostrarán respuesta a la tiazida, sin embargo, los pacientes con un defecto ROMK mostrarán buena respuesta a la furosemida y a las tiazidas y aquellos con un defecto en el ClC-Kb no mostrarán unar espuesta a la tiazida pero si una respuesta normal a la furosemida (15).

La hipopotasemia puede influir en el retraso del crecimiento por una reducción en la respuesta de IGF-I a la hormona del crecimiento. Pero la corrección del potasio no corrige la falta de crecimiento, lo que sugiere que otros mecanismos pueden estar implicados. Algunos han encontrado niveles altos de hormona del crecimiento, pero otros niveles bajos (14).

Algunos pacientes presentan niveles elevados de insulina e hiperplasia de los islotes de Langerhans, posiblemente por intolerancia a la glucosa. Cuando la alcalosis y la hipopotasemia se corrigen, la intolerancia a la glucosa puede persistir (14).

La biopsia no es necesaria para diagnosticar el SB. Se observa hiperplasia del aparato yuxtaglomerular, aunque a veces puede no estar presente o su alteración ser leve (14). En ocasiones se ha descrito la pérdida de la proteína de Tamm-Horsfall (21).También se han descrito infiltrados inflamatorios con áreas de fibrosis intersticial, atrofia tubular focal con engrosamiento de las membranas basales y degeneración del epitelio tubular, hipercelularidad con aumento de la matriz mesangial focal y segmentaria. Las lesiones serán menores en los defectos del canal ROMK con respecto al NKCC2 (9).

Su heterogeneidad clínica y genética puede requerir un análisis molecular para poder diferenciar sus diferentes tipos y con el SG. Esta variedad genética dificulta el análisis mutacional, ya que en ocasiones se deben analizar varios genes. El estudio genético se puede realizar analizando el ADN total extraído y purificado a partir del eucocitos periféricos en muestras de sangre. Exones específicos de los genesSLC12A1, KCNJ1, CLCNKBySLC12A3pueden seramplificados por PCR específicos utilizando pares de primers. Luego, la amplificación de los productos PCR son purificados y sometidos a la secuenciación (15).

El diagnóstico prenatal en etapas tempranas del embarazo se puede realizar por biología molecular en amniocitos obtenidos mediante biopsia de las vellosidades coriónicas o, en épocas más tardías, por el aumento del cloro en el líquido amniótico (21).Los niveles de aldosterona, tanto el líquido amniótico como en la sangre de la madre, podrá encontrarse aumentados hacia las 27 semanas de gestación, cuando aún los niveles de electrolitos en el líquido amniótico no se encuentran alterados, pudiendo constituir un marcador temprano en el diagnóstico del feto afectado (38). También, la concentración de proteínas será menor en el líquido amniótico comparado con los polihidramnios de otras causas o en los embarazo no afectados (39).

El examen microscópico de la placenta en los casos no tratados mostrará extensa mineralización de las vellosidades coriónicas, aunque algunos casos tratados con indometacina revelaron solo calcificaciones focales y aterosis aguda de los vasos (40).

\section{Tratamiento}

No hay un tratamiento específico. Inicialmente se deben reducir las pérdidas de líquidos y electrolitos y corregir los déficit presentes. Estos pacientes son especialmente sensibles a la deshidratación por lo cual deben ser estrechamente vigilados durante las enfermedades agudas, donde se aumentan las pérdidas de líquidos o disminuye su ingesta. En las primeras semanas de vida en el Bartter antenatal pueden requerirse volúmenes de líquidos tan altos como $500 \mathrm{ml} / \mathrm{kg} /$ día y aportes de sodio de hasta $45 \mathrm{mEq} / \mathrm{kg} /$ día.

La rehidratación parenteral con solución salina isotónica puede ser tan importante como la reposición de potasio para el tratamiento de hipopotasemia severa, ya que estos pacientes cursan con depleción crónica de volumen. Se deben evitar las soluciones glucosadas ya que pueden redistribuir el potasio del espacio ex- 
tracelular al intracelular y así agravar la hipocalemia, corriendo el riesgo de generar arritmias cardiacas y rabdomiólisis. En pacientes con el intervalo QT prolongado, ya sea por la hipocalemia en sí o por factores congénitos, se debe intentar que el potasio sérico no sea menor de $3 \mathrm{mEq} / \mathrm{L}$. Si un paciente con SB tiene un intervalo QT prolongado o presenta una miocardiopatía hipertrófica, anomalías de las arterias coronarias, síndrome de Marfan, estenosis aórtica o el síndrome de Wolff-Parkinson-White, la realización de ejercicio, especialmente competitivo, se asocia con aumento en el riesgo de muerte cardiaca súbita (41).

Las pérdidas de potasio en las 2 a 3 primeras semanas de vida son bajas, por lo que generalmente su suplemento es posterior a esta edad (2), llegando a requerir entre 5 a $10 \mathrm{mEq} / \mathrm{kg} /$ día (un adulto puede llegar a requerir $500 \mathrm{mEq}$ por día), los cuales son dados en 4 dosis divididas, ajustando las formulas a una concentración de potasio en los líquidos a administrar de 40 a $50 \mathrm{mEq} / \mathrm{L}$ (14)(29). Grandes cantidades de potasio exógeno pueden aumentar las pérdidas renales de potasio y así incrementar los niveles de aldosterona (14). Su administración aislada generalmente es inefectiva ya que la mayor parte se pierde por la orina (21). Cuando se inicia la indometacina, su dosis puede ser disminuida o hasta retirada hacia los 2 años de vida (22), especialmente en el Bartter tipo II (3).

El uso de ahorradores de potasio no es tan útil como en el SG (12)y, aunque tienen la ventaja de preservar el magnesio, pueden disminuir el volumen intravascular especialmente en lactantes y niños pequeños. Es preferible la espironolactona sobre la amilorida, ya que bloquea la acción de la aldosterona (4). Su administración no disminuye la hiperplasia del aparato yuxtaglomerular (14) y puede agravar la hipercalciuria con la subsecuente nefrocalcinosis (2). Su utilidad en general es limitada, variable (19) y transitoria (21). Su uso debe hacerse con precaución ya que cuando se presentan estados de hipovolemia, como en la diarrea o el vómito, donde la función renal se reduce críticamente, puede pasar de hipocalemia a hipercalemia, con el consiguiente riesgo para el paciente (3). La dosis de espironolactona es de $1 \mathrm{a}$ $1,5 \mathrm{mg} / \mathrm{kg} /$ día (9).

Teniendo en cuenta la fisiopatología del síndrome de Bartter,la inhibición dela síntesis de prostaglandinas a nivel renal y sistémico por los antiinflamatorios no esteroideos (AINES), los convierten en la piedra angular del manejo. Reducen en forma espectacular la excreción de prostaglandinaE2urinariaen cerca deun 65\% (14), la hiperreninemia, el hiperaldosteronismo e incrementa el potasio sérico, aunque en general no se logran valores por encima de $3,5 \mathrm{mEq} / \mathrm{L}$. Esto mejora la poliuria, convierte la hipostenuria en isostenuria, reduce la hipercalciuria, estimula la recuperación del crecimiento (1)(29), mejora la fuerza muscular, la actividad física, los síntomas sistémicos del hiperprostaglandismo y revierte la resistencia a los efectos presores de la angiotensina II.No previenen la nefrocalcinosis (14). A pesar de disminuir la producción de prostaglandinas, el defecto tubular de reabsorción de cloro persistirá (14). El mantenimiento de una volemia en el período postnatal inmediato es importante antes de comenzar la terapia con AINES, ya que podría precipitar la insuficiencia renal aguda si el volumen extracelular esta disminuido. La mayor experiencia se tiene con la indometacina,la cual permanece como la droga de choque por ser quizás la más eficaz y la mejor tolerada por los niños (3).

La dosis de inicio es de $0,5 \mathrm{mg} / \mathrm{kg} /$ día, aumentando gradualmente hasta 2,5 (máximo 5 ) mg/kg/día,de acuerdo a sus efectos sobre la producción de orina, la síntesis renal dePGE2y los niveles séricos de aldosterona (1)(29), teniendo en cuenta que a dosis mayores de $3 \mathrm{mg} / \mathrm{kg} /$ día puede ser nefrotóxica (2)(9). También se puede utilizar el ibuprofeno a 15 a $30 \mathrm{mg} / \mathrm{kg} / \mathrm{día}(42)$ y otros AINES como el ketoprofeno (2)(29) y el ácido acetilsalićlico (5mg/kg/día en 2 dosis) (43).Pueden ocasionar nauseas, vomito, dolor abdominal, toxicidad hematopoyética y hepática, pseudotumor cerebral y, con su uso crónico,gastritis,ulcera péptica (21) y hemorragia digestiva (22). Puede estar indicado el uso de inhibidores de la bomba de protones (3). Se deben utilizar con precaución en recién nacidos(debido al riesgo de enterocolitis) y cuando se presenta disminución de la filtración glomerular (que es dosis dependiente y reversible con su suspensión) (2) y nefrotoxicidad (que no siempre es reversible) (14), como la necrosis tubular aguda (22). Por esto se recomienda iniciar a las 4 a 6 semanas después del nacimiento, vigilando estrechamente la posibilidad de enterocolitis y, si esta se presenta, se debe suspender inmediatamente el medicamento (2). No se deben dar en el feto por los efectos adversos sobre el ductus arterioso (14) y el desarrollo del riñón (9).

Estos pueden reducirse mediante el usode la COX-2selectivos como el rofecoxib, que muestra un efecto 
similar sobre la pérdida de sal renal, la hiperprostaglandinemia e hiperreninemia, pero puede afectar negativamente la presión arterial (1),ocasionar un mayor riesgo cardiovascular (3), se ha descrito un caso de insuficiencia renal reversible (9) y aun la experiencia con su uso es limitada (42).El Bartter tipo II es muy sensible a la indometacina, requiriendo en ocasiones dosis inferiores a $1 \mathrm{mg} / \mathrm{kg} /$ día, sin suplementos de potasio (18). La administración de indometacina en recién nacidos con defectos $\mathrm{ROMK}$ puede ocasionar insuficiencia renal oligúrica e hiperpotasemia grave (9).El Bartter tipo IV es resistente a la indometacina (18). La eficacia de la indometacina se mantiene por periodos prolongados de tiempo, aunque en ocasiones se observa recurrencia de la hiperreninemia y la hipocalemia, debiendo reajustar la dosis o administrar en conjunto con ahorradores de potasio (21).

Los inhibidores de la enzima convertidora de la angiotensina, los bloqueadores de los receptores de la angiotensina o los inhibidores directos de la renina sólo se deben dar si persiste una hipocalemia menor de $3 \mathrm{mEq} / \mathrm{L}$ a pesar del uso de los AINES y los suplementos de potasio (3).Aumentan los niveles séricos de potasio y disminuyen la producción de angiotensina II y de aldosterona, y aunque se han utilizado con algún éxito, todavía no hay una recomendación clara. Su introducción debe ser lenta por el riesgo de causar hipotensión(42), la que generalmente dura 3 a 4 días (4). En el Bartter tipo IV podrían ser útiles asociados a la indometacina, ya que este grupo de pacientes responden mal a los AINES (9). También se deben considerar en los pacientes que presentan proteinuria como una de las complicaciones a largo plazo de la enfermedad (3). Recientemente se ha descrito el uso del bloqueador del receptor de la renina aliskiren en el SB, logrando disminuir las necesidades de suplemento de potasio y de espironolactona, corrigiendo la hipocalemia (19).

El propanolol disminuye la actividad de la renina y la aldosterona en algunos pacientes con SB, pero no mejora la hipocalemia y puede disminuir mucho la presión arterial, aumentando así paradójicamente los niveles de renina y aldosterona (14).

Cuando hay hipomagnesemia se deben dar suplementos de magnesio, lo que ayuda también a incrementar la eficiencia de los suplementos de potasio (21), aunque su corrección es generalmente difícil (9) y se puede acompañar de trastornos gastrointestinales (3).
No hay tratamiento para la nefrocalcinosis y el uso de tiazidas para disminuir la hipercalciuria está contraindicada, ya que pueden aumentar la poliuria y la hipocalemia (7)(42), interfiriendo con los mecanismos compensatorios del túbulo contorneado distal (9). En el Bartter tipo V cuando hay hipocalcemia sintomática se puede utilizar la vitamina $\mathrm{D}$, aunque con precaución, ya que puede agravar la nefrocalcinosis y la insuficiencia renal (18). En el Bartter tipo $\mathrm{V}$ el uso de hidroclorotiazida puede reducir la excreción urinaria de calcio y mantener las concentraciones de calcio sérico cercanas a lo normal, lo que permite lareducción del uso de vitamina D (9).

Cuando hay deficiencia de hormona del crecimiento asociada, los pacientes con SB responderán a su suplencia (14).

La nefrectomía preventivaseguida del trasplanterenal, puede corregir las anormalidadesmetabólicas ymantener una adecuada función del injerto, la cual debe ser considerada especialmente en aquellos pacientes que no responden al manejo medicamentoso, como es el Bartter tipo IV(9).

\section{Bartter y embarazo}

Pueden presentarsedos situaciones: la mujer con un $\mathrm{SB}$ que se embaraza y cuyo feto puede o no estar afectado y la mujer que no está afectada pero el feto sí. En general, el feto se ve protegido de la hipocalemia materna por el transporte activo del potasio a través de la placenta, teniendo mayores concentraciones séricas que la madre (44). Durante el embarazo los niveles de potasio materno no son estables y es probable que no aumenten (44).En las madres con un feto afectado y polihidramnios se aconseja la amniocentesis seriada para reducir el volumen del líquido amniótico y dar suplementos de cloruro de potasio para prevenir la hipocalemia fetal.

Algunos autores han utilizado indometacina en el periodo prenatal para prevenir la nefrocalcinosis grave del feto (40) al igual que para disminuir el polihidramnios y por ende prevenir el parto prematuro (44)(45) (46), aunque se ha descrito la presencia de bradicardia fetal durante su uso (47) y un potencial efecto teratógeno (44), aconsejándose no utilizar por largos periodos y quizás como un último recurso (44). En las madres con SB que se embarazan y presentan hipocalemia, especialmente si el potasio sérico es 
menor de $3 \mathrm{mEq} / \mathrm{L}$, se aconseja administrar suplementos de potasio y sodio, aunque generalmente estos no van a corregir adecuadamente la hipocalemia presente. El uso de ahorradores de potasio en estos casos no ha demostrado mayor beneficio (48) y sólo se deben administrar si la hipocalemia es severa y no ha mejorado con los suplementos de potasio (44). Aunque algunos autores han utilizado la amiloriday la espironolactona sin efectos en el feto (44)(49), este último diurético posee un efecto antiandrogénico, por lo que algunos autores no aconsejan su uso por el riesgo de ocasionar una virilización incompleta en el varón, aunque otros consideran que este temor es infundado (44).

También se ha utilizado inhibidores de la ECAasociados a espironolactona (44). La exposición del feto a los diuréticos, con o sin captopril, se haasociado a parto prematuro (44). Los inhibidores de la ECA se han descrito con un potencial efecto teratógeno, por lo que su uso debe ser en pacientes que no han respondido a los suplementos de potasio con o sin ahorradores de potasio (44).Algunos embarazos en su tercer trimestre pueden presentar oligoamnios, ya sea asociado al uso de diuréticos ahorradores de potasio o no, al parecer ocasionado por la deshidratación materna que disminuye el flujo placentario, lo que disminuye el flujo renal fetal, el cual es el mayor origen del líquido amniótico. Al contrario, la sobrehidratación materna generará mayor polihidramnios (44). Si se presenta hipomagnesemia, se deben dar suplementos de magnesio (44). A pesar de todo lo anotado, estos embarazos generalmente darán a luz recién nacidos sanos (48), aún si han sido expuestos a amilorida, espironolactona o captopril, con un desarrollo físico y psicomotor normal (44).

\section{Pronóstico}

Generalmente es bueno con un tratamiento precoz y un adecuado control metabólico (10), manteniendo una adecuada tasa de filtración glomerular y permitiendo un crecimiento y desarrollo puberal normales (21)(27).Un artículo reciente muestra que el grado de hipopotasemia no se correlaciona con la filtración glomerular y que las pérdidas de sodio y agua recurrentes y el hiperaldosteronismo secundario consiguiente pueden desempeñar el papel más importante en la etiología de la nefropatía hipopotasémica (50).Este tipo de trastornos generalmente son severos en el periodo neonatal y la infancia temprana, pero luego mejorarán progresivamente, lo que permite disminuir la intensidad del tratamiento (3). Algunas instituciones retiran la medicación bajo condiciones controladas cada 3 a 4 años, pudiendo de esta manera identificar aquellos pacientes con trastornos leves o disfunciones tubulares transitorias durante el periodo neonatal (3).

En un grupo pequeño de pacientes, especialmente los no tratados o mal controlados, la hipocalemia crónica, la nefrocalcinosis y la terapia crónica con indometacina pueden llevar a nefritis tubulointersticial crónica con falla renal crónica terminal (10)(21), especialmente en el Bartter tipo IV, el cual, como se comentó previamente, no responde a la indometacina (21) (27). El pronóstico renal es incierto en el tipo II con nefrocalcinosis grave (27).La nefrocalcinosis no siempre está presente cuando se desarrolla insuficiencia renal (22). El desarrollo psicomotor en la mayoría de los niños es normal, con una adecuada integración escolar, pero unos pocos presentan dishabilidades en su neurodesarrollo (trastornos motores, problemas de atención, dislexia, epilepsia compleja) posiblemente como complicación de su prematuridad asociada a los desequilibrios hidroelectrolíticos (22).

Los pacientes con hipocalemia y que tienen QT prolongado tienen mayor riesgo de presentar arritmias cardiacas, pudiendo ocasionar síncope o muerte súbita (41). La hipocalemia severa puede causar rabdomiólisis. Las consecuencias inmediatas de rabdomiólisis incluyen hiperpotasemia (e hiperfosfatemia) resultante de la liberación de potasio y fósforo del músculo dañado, que a su vez puede provocar arritmias cardíacas y daño renal agudo. Por este motivo, cuando estos pacientes se presentan con diarrea o vómito deben tener una estrecha vigilancia especialmente cuando hay una severa hipocalemia con un potasio sérico igual o menor de $2 \mathrm{mEq} / \mathrm{L}$.

La historia de síncope es un importante predictor de que se pueden presentar eventos cardiovasculares potencialmente mortales. Por esto, la recomendación es que estos pacientes no participen en deportes competitivos, ya que tienen una capacidad disminuida de la función ventricular izquierda para adaptarse al ejercicio. Igualmente, se debe tener en consideración el uso las sustancias o medicamentos que puedan prolongar el QT como pueden ser la ingesta aguda de alcohol, los agentes antiarrítmicos, algunos antihistamínicos, algunos antitusivos, macrólidos, antifúngicos, psicotrópicos, $\beta 2$-agonistas adrenérgicos o cisaprida, 
ya que pueden precipitar arritmias cardíacas. Además, el abuso de alcohol y drogas ilícitas como la cocaína y el éxtasis y algunos medicamentos como las estatinas y los fármacos antipsicóticos, que pueden ser potencialmente miotóxicos, pueden en estos pacientes causar desde un aumento asintomático en la sangre de la creatina quinasa hasta una rabdomiolisis aguda, por lo que se deben evitar (41).

\section{Importancia de los heterocigotos}

Las mutaciones heterocigotas de un solo alelo de los genes SLC12A3 (NCCT), SLC12A1 (NKCC2) y KCNJ1 (ROMK) producen reducción significativa de la presión arterial (entre 5 y $7 \mathrm{~mm} / \mathrm{Hg}$ ), tanto para la presión sistólica como la diastólica,al igual que protegen del desarrollo de hipertensión, no habiendo diferencias entre hombres y mujeres, ni relación con el índice de masa corporal. Esta tendencia es ligeramente mayor con el KCNJ1.Esta disminución de la presión arterial se mantiene con la edad, aumentando solo ligeramente con los años: $5.7 \mathrm{~mm} / \mathrm{Hg}$ más baja a los 40 años, $6.4 \mathrm{~mm} / \mathrm{Hg}$ a los 50 y $9.0 \mathrm{~mm} / \mathrm{Hg}$ a los 60 . Los portadores heterocigotos de la mutación, a la edad de 60 años, tienen una probabilidad59\% menorde sufrir hipertensión arterial, siendo similar para hombres y mujeres (16). Estos resultados tienen implicaciones para el estudio de la genética de la hipertensión (16). La prevalencia del SB se estima en 1 por millón de habitantes y el de Gitelman en 1 por 40.000, lo que sugiere que los alelos heterocigotos estarán presentes en al menos $1 \%$ de la población (16). Habrá que ver si estos portadores heterocigotos tienen menor morbilidad y mortalidad cardiovascular que los no portadores.

Contrario a lo anterior, un polimorfismo genético del canal ClC-Kb (T481S), presente en el $22 \%$ de la población de Ghana y en el $12 \%$ de los blancos (51), se asocia con hipertensión arterial al aumentar el transporte tubular de cloro (21)(51), presentando los individuos afectados cifras sistólicas de $6 \mathrm{mmHg}$ y diastólicas de $4 \mathrm{mmHg}$ en promedio más altas que los no portadores, una concentración plasmática de sodio más alta, una menor tasa de filtración glomerular y una prevalencia mayor en pacientes hipertensos (45\% versus $25 \%$ ) (51).

\section{Agradecimientos}

Deseamos dar las gracias por el apoyo a la realización del trabajo, el aporte bibliográfico y la revisión del tema, al grupo de Epidemio- logia del Hospital El Tunal, la Dra. Narda Olarte y el Jefe Alberto Valderrama y a nuestros compañeros de trabajo, los pediatras Gloría Galán y Diocel Lancheros. Sus consejos y correcciones fueron siempre oportunos y adecuados. Mil gracias a ellos.

\section{Bibliografía}

1. Waldegger S. Bartter, Gitelman, and Related Syndromes.In: Denis F Geary and Franz Schaefereditores. Comprehensive Pediatric Nephrology.1st ed. Philadelphia. Mosby, Elsevier. 2008. p. 450-9.

2. Amirlak I and Dawson KP. Bartter syndrome: an overview. Q J Med 2000;93:207-215.

3. Seyberth HW and Schlingmann KP. Bartter- and Gitelman-like syndromes: salt-losing tubulopathies with loop or DCT defects. PediatrNephrol. Published online: 19 Abril 2011.

4. Rose BD y Post TW.Asa de Henle y mecanismo de contracorriente. En Rose \& Post editores. Electrolitos y equilibrioácidobase de bolsillo.Madrid. MarbanLibros SL. 2007. p. 112-42.

5. Welling PA and Ho K. A comprehensive guide to the ROMK potassium channel: form and function in health and disease. Am J Physiol Renal Physiol. 2009; 297: F849-F863.

6. Lehmann-Horn F and Jurkat-Rott K. Voltage-Gated Ion Channels and Hereditary Disease. Physiological reviews. 1999;79(4):1.317-72.

7. Chadha V and Alon US.Hereditary Renal Tubular Disorders. Seminars in Nephrology. 2009;29(4):399-411.

8. Schlingmann KP, Konrad M, Jeck N, et. al. Salt Wasting and Deafness Resulting from Mutations in Two Chloride Channels. N Engl J Med. 2004;350:1314-9.

9. Devuyst O, Konrad M, Jeunemaitre X and Zennaro MC. Tubular Disorders of Electrolyte Regulation. Pediatric Nephrology. Ellis D. Avner, William E. Harmon, Patrick Niaudet, Norishige Yoshikawa (Eds.). Springer. 2009. p. 929-40.

10. MacRae Dell K and Avner ED. Bartter/Gitelman syndromes and other inherited tubular transport abnormalities. Nelson Texbook of Pediatrics. p. 2201-2.

11. Gennari J. Hypokalemia. N Eng J Med. 1998;339(7):451-8.

12. Goilav B and Trachtman H. Disorders of Potassium Balance. In Fluid and Electrolytes in Pediatrics.A Comprehensive Handbook.Edited by Leonard G. Feld and Frederick J. Kaskel. Humana Press. 2010. p. 81-3.

13. Carrascal Guzmán M y de Castaño I. Evaluación de niños con tubulopatías primarias. Enfoques en Nefrología Pediátrica. Consuelo Restrepo de Rovetto, Iris de Castaño y Jaime Manuel Restrepo editores. AsociaciónColombiana de NefrologíaPediátrica. 2010. p. 52-53.

14. Shaer AJ.Inherited Primary Renal Tubular Hypokalemic Alkalosis: A Review of Gitelman and Bartter Syndromes.Am J Med Sci. 2001;322(6):316-32.

15. Nozu K, Iijima K, Kanda $\mathrm{K}$ et al. The Pharmacological Characteristics of Molecular-Based Inherited Salt-Losing Tubulopathies.J ClinEndocrinolMetab. 2010; 95: E511-E518.

16. Ji W, Foo JN, O'RoakBJ, et al. Rare independent mutations in renal salt handling genes contribute to blood pressure variation. 2008;40(5):592-99.

17. García Nieto V y Claverie-Martín F. Enfermedad de Bartter con sordera neurosensorial (Bartter tipo IV). Una entidad descrita hace solo diez años. Nefrología. 2005;25(6):596-601.

18. Vallés PG. Alteraciones en la homeostasis del potasio. Nefrología pediátrica. Editores Gustavo Gordillo Paniagua, Ramón A. Exeni y Jorge de la Cruz. Terceraedición.Elsevier. 2009. p. 161-63. 
19. Bell DSH. Successful Utilization of Aliskiren, a Direct Renin Inhibitor in Bartter Syndrome. Southern Medical Journal. 2009;102(4):413-15.

20. Kurtz I. Molecular pathogenesis of Bartter's and Gitelman's syndromes. Kydney International. 1998(54):1398-1410.

21. Rodríguez-Soriano J. Síndrome de Bartter y síndromes afines. Nefrología pediátrica. Editores Gustavo Gordillo Paniagua, Ramón A. Exeni y Jorge de la Cruz. Tercera edición. Elsevier. 2009. p. 400-409.

22. Brochard K, Boyer O, Blanchard A, et al.Phenotype-genotype correlation in antenatal and neonatal variants of Bartter syndrome. Nephrol Dial Transplant (2009) 24: 1455-1464.

23. Bockenhauer D, Feather S, Stanescu HC et al.Epilepsy, Ataxia, Sensorineural Deafness, Tubulopathy, and KCNJ10 Mutations. Among Patients Suffering from Bartter and Gitelman Syndromes - Summary N Engl J Med 2009;360:70.

24. Urbanova M, Reiterova J, Stekrova J, et al.DNA Analysis of Renal Electrolyte Transporter Genes of Mutation Screening. Folia Biologica (Praha). 2011;57:65-73.

25. Roselle Abraham M, Jahangir A, Aleekseev AE and Terzic A.Channelopathies of inwardly rectifying potassium channels. Faseb J. 1.999;13:1901-1910.

26. RodríguezSoriano J. Tubulopatías renales hereditarias: de la clínica a la biología molecular. Nefrología. 2003;23(1):71-83.

27. Ariceta G y Aguirre M. Tubulopatías en la infancia que progresan hacia la enfermedad renal crónicaNefroPlus. Sociedad Española de Nefrología. 2.011;4(1):11-8.

28. Wagner CA.New roles for renal potassium channels. JNeprhrol.2010;23(01):5-8.

29. Moxey-Mims M and Goodyer P.A Physiologic Approach to Hereditary Tubulopathies.In Fluid and Electrolytes in Pediatrics.A Comprehensive Handbook.Edited by Leonard G. Feld and Frederick J. Kaskel. Humana Press. 2010. p. 331-3.

30. Janssen AGH, Scholl U, Domeyer C et al. Disease-Causing Dysfunctions of Barttin in Bartter Syndrome Type IV. JASN. J Am SocNephrol. 2009;20(1):145-53.

31. Sánchez, A. El sensor-receptor de calcio y patologías asociadas. Revista Argentina de Endocrinología y Metabolismo. 2006;43(4):224-32

32. Stechman MJ, Loh NY and Thakker RV. Genetic causes of hypercalciuric nephrolithiasis. PediatrNephrol. 2009;24:232132.

33. Riccardi D and Brown EM.Physiology and pathophysiology of the calcium-sensing receptor in the kidney. Am J Physiol Renal Physio. 2010;298:F485-F499.

34. D'Souza-Li L.The Calcium-Sensing Receptor and Related Disease.ArqBrasEndocrinolMetab. 2006; 50(4):628-39.

35. Rolim AL, Lindsey SC, Kunii IS et al. Ion channelopathies in endocrinology: recent genetic findings and pathophysiological insights. Arq Bras EndocrinolMetab. 2010;54 (8).

36. Mejía Gaviria N. Valores normales y fórmulas en nefrología pediátrica. Enfoques en Nefrología Pediátrica. Consuelo Res- trepo de Rovetto, Iris de Castaño y Jaime Manuel Restrepo editores. Asociación Colombiana de Nefrología Pediátrica. 2010. p. 305-9.

37. Srivastava T and Schwaderer A.Diagnosis and management of hypercalciuria in children. Current Opinion in Pediatrics 2009;21:214-219.

38. Nakanishi T, Suzumori N, Mizuno H, et al.Elevated aldosterone in amniotic fluid and maternal blood has diagnostic potential in pregnancies complicated with a fetus of Bartter syndrome. Fetal DiagnTher. 2005 Nov-Dec;20(6):481-4.

39. Garnier A, Dreux S, Vargas-Poussou R, et al. Bartter syndrome prenatal diagnosis based on amniotic fluid biochemical analysis. Pediatr Res. 2010 Mar;67(3):300-3.

40. Dane B, Dane C, Aksoy F, et al. Antenatal Bartter syndrome: analysis of two cases with placental findings. Fetal PediatrPathol. 2010;29(3):121-6.

41. Cortesi C, Lava SAG, Bettinelli A et. al. Cardiac arrhythmias and rhabdomyolysis in Bartter-Gitelman patients.PediatrNephrol.2010;25:2005-2008.

42. Waz WR.Diagnosis and Treatment of Metabolic Alkalosis.In Fluid and Electrolytes in Pediatrics.A Comprehensive Handbook.Edited by Leonard G. Feld and Frederick J. Kaskel. Humana Press. 2010. p. 250.

43. Ouz SS, Gökmen T, Erdeve O et al.Acetyl salicylic acid treatment in neonatal Bartter síndrome.PediatrNephrol. Published online: 10 Mayo 2011.

44. Mascetti L, Bettinelli A, MD, Giacomo D. Simonetti GD, et al. Pregnancy in Inherited Hypokalemic Salt-Losing Renal Tubular Disorder. Obstet Gynecol. 2011;117:512-6.

45. Tourne G, Collet F, Varlet MN, et al. Prenatal Bartter's syndrome. Report of two cases. J GynecolObstetBiolReprod (Paris). 2003 Dec;32(8):751-4.

46. Bhat YR, Vinayaka G, Vani R, et al.Antenatal Bartter syndrome: a rare cause of unexplained severe polyhydramnios. Ann Trop Paediatr. 2011;31(2):153-7.

47. Dane B, Yayla M, Dane C, Cetin A. Prenatal diagnosis of Bartter syndrome with biochemical examination of amniotic fluid: case report. Fetal DiagnTher. 2007;22(3):206-8.

48. Luqman A, Kazmi A, and Wall BM. Bartter's syndrome in pregnancy: review of potassium homeostasis in gestation. Am J Med Sci. 2009 Dec;338(6):500-4.

49. Deruelle P, Dufour P, Magnenant E, et al. Maternal Bartter's syndrome in pregnancy treated by amiloride. Eur J ObstetGynecolReprod Biol. 2004 Jul 15;115(1):106-7.

50. Walsh SB, Unwin E, Vargas-Poussou R, et al.Does hypokalaemia cause nephropathy? an observational study of renal function in patients with Bartter or Gitelman syndrome. QJM.2011 Jun 25.[Epub ahead of print].

51. Jeck N, Waldegger S, Lampert A, et al. Activating mutation of the renal epithelial chloride channel $\mathrm{ClC}-\mathrm{Kb}$ predisposing to hypertension. Hypertension.2004; 43:1175-81. 